\title{
Polymer-MXene composite films formed by \\ MXene-facilitated electrochemical \\ polymerization for flexible solid-state \\ microsupercapacitors
}

Leiqian Qin, Quanzheng Tao, Xianjie Liu, Mats Fahlman, Joseph Halim, Per O A Persson, Johanna Rosén and Fengling Zhang

The self-archived postprint version of this journal article is available at Linköping University Institutional Repository (DiVA):

http://urn.kb.se/resolve?urn=urn:nbn:se:liu:diva-158325

N.B.: When citing this work, cite the original publication.

Qin, L., Tao, Q., Liu, X., Fahlman, M., Halim, J., Persson, P. O A, Rosén, J., Zhang, F., (2019),

Polymer-MXene composite films formed by MXene-facilitated electrochemical polymerization for flexible solid-state microsupercapacitors, Nano Energy, 60, 734-742.

https://doi.org/10.1016/j.nanoen.2019.04.002

Original publication available at:

https://doi.org/10.1016/j.nanoen.2019.04.002

Copyright: Elsevier

http://www.elsevier.com/

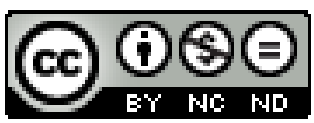




\section{Polymer-MXene Composite Films formed by MXene- facilitated Electrochemical Polymerization for Flexible}

\section{Solid-State Microsupercapacitors}

Leiqiang Qin ${ }^{\mathrm{a}, *}$, Quanzheng Tao ${ }^{\mathrm{a}}$, Xianjie Liu ${ }^{\mathrm{a}}$, Mats Fahlman ${ }^{\mathrm{a}}$, Joseph Halimª ${ }^{\mathrm{a}}$ Per O. Å. Persson $^{\mathrm{a}}$, Johanna Rosen ${ }^{\mathrm{a}, *}$, Fengling Zhang ${ }^{\mathrm{a}, \mathrm{b}, *}$

${ }^{a}$ Department of Physics, Chemistry and Biology (IFM), Linköping University, SE-581 83 Linköping, Sweden.

${ }^{\mathrm{b}}$ Guangzhou Key Laboratory of Vacuum Coating Technologies and New Energy Materials, Physics Department, Jinan University, Guangzhou, 510632, P. R. China.

*Corresponding authors: E-mail: leiqiang.qin@liu.se; johanna.rosen@liu.se; fengling.zhang@liu.se

\section{Abstract:}

Materials with tailored properties are crucial for high performance electronics applications. Hybrid materials composed of inorganic and organic components can possess unique merits for broad application by synergy between the advantages the respective material type offers. Here we demonstrate a novel electrochemical polymerization (EP) enabled by a 2D transition metal carbide MXene for obtaining conjugated polymer-MXene composite films deposited on conducting 
substrates without using traditional electrolytes, indispensable compounds for commonly electrochemical polymerization. The universality of the process provides a novel approach for EP allowing fast facile process for obtaining different new polymer/MXene composites with controlled thickness and micro-pattern. Furthermore, high performance microsupercapacitors and asymmetric microsupercapacitors are realized based on the excellent composites benefiting from higher areal capacitance, better rate capabilities and lower contact resistance than conventional electropolymerized polymers. The AMSCs exhibit a maximum areal capacitance of $69.5 \mathrm{mF} \mathrm{cm}^{-}$ ${ }^{2}$, an ultrahigh volumetric energy density $\left(250.1 \mathrm{mWh} \mathrm{cm}^{-3}\right)$ at $1.6 \mathrm{~V}$, and excellent cycling stability up to 10000 cycles. The excellent electrochemical properties of the composite polymerized with MXene suggest a great potential of the method for various energy storage applications.

\section{Introduction}

Conductive polymers are recognized as a class of organic materials with unique advantages over inorganic solids, including low cost, easy processing, compatibility and tunable intrinsic properties (electronic, optical, conductivity and stability) [1-3], which make them good candidates in a wide range of application areas, such as smart windows [4], thermoelectrics [5], biosensors [6], corrosion protection [7], light-emitting diodes [8] and energy storage devices [9-11]. In recent years, many different synthetic methods for conductive polymers under mild conditions have been developed, which vastly extends the possibility to advance the fabrication process for energy storage devices [12-15]. In situ electrochemical polymerization (EP) shows unique advantages as the coupling reaction occurs in the electrolyte solution and the conductive polymer film is deposited directly on the destination electrode in one step [16-20]. The growth rate and thickness of the polymer film can be easily modulated by controlling the applied potential (or current density) and the total amount of charge passed through the cell, respectively [21]. The electrolyte 
solution of EP generally contains three components: solvent, supporting electrolyte, and monomer [22]. However, the supporting electrolyte is an indispensable part that plays a vital role in electrochemical polymerization process. During the EP process, electrolyte ions will act as counter ions trace doped into the polymer film, which then obtain the organically conductive polymer with excellent performance and variable conductivity. At present, it is impossible to obtain an organicinorganic composite film in one-step by the EP methodwhich will severely limits the application of EP for composite films despite the inherent advantages.

MXenes, discovered in 2011, is a comparatively new class of 2D transition metal carbides, carbonitrides and nitrides [23]. They are produced by etching the 'A' layers from their ternary carbides precursors, so called MAX phases [24], where M is a transition metal, A is an A-group element such as $\mathrm{Al}, \mathrm{Ga}$ or $\mathrm{Si}$, and $\mathrm{X}$ is $\mathrm{C}$ and/or $\mathrm{N}$ [25-26]. The most studied MXene to date is $\mathrm{Ti}_{3} \mathrm{C}_{2} \mathrm{~T}_{\mathrm{x}}$ (in short $\mathrm{Ti}_{3} \mathrm{C}_{2}$ ), where $\mathrm{T}_{\mathrm{x}}$ represents surface terminations, typically $\mathrm{O}, \mathrm{OH}$ and/or $\mathrm{F}$ [2728]. Most recently, a new type of MAX phase, $i$-MAX, was discovered, realizing a MXene with in-plane vacancy ordering [29-30]. Apart from exhibiting a high conductivity, the first vacancy MXene, Mo1.33 C, has shown a high potential for supercapacitor applications [30-31]. Recently, using spontaneous electron transfer between MXene and organic monomer to promote the polymerization of organic monomers and form a composite film [32-33] and preparation of composite films by physical mixing of MXene and a conducting polymer [31] have achieved great success. However, these methods take a long time and cannot directly result in a patterned composite film in one step, which then had to be obtained by vacuum filtration. In a colloidal solution, typically negatively charged MXene [32-34] is very similar to electrolyte ions. If MXene is introduced into the EP process, which can act as counter ions by self-assemble with positively charged conductive polymer chain to form a molecular-level contact MXene-doped conductive 
polymer film in one step with high efficiency on the electrode surface. The MXene-doped conductive polymer could potentially provide an electrode architecture with improved performance for energy storage devices.

Herein, we demonstrate a novel in situ electrochemical polymerization process of 2D MXenedoped conductive polymer films enabled by MXene without use of conventional electrolytes. During the EP process, the colloidal solution of MXene not only provides a highly conductive solvent, but also simultaneously self-assembles into the polymer film during the polymerization process with high doping content compared to conventional electrolytes to form a molecular-level conjugated polymer-MXene composite films (Figure 1A). Furthermore, high performance solid state microsupercapacitors (MSCs) based on the composite films are realized, which exhibit excellent rate performance, great cycling stability, and ultrahigh energy density. Moreover, in order to further increase the cell voltage and energy density, asymmetric microsupercapacitors (AMSCs) are constructed based on the in situ EP composite films and $\mathrm{MnO}_{2}$, achieving a high energy density of $250.1 \mathrm{mWh} \mathrm{cm}^{-3}$ and power density of $32.9 \mathrm{~W} \mathrm{~cm}^{-3}$ at $1.6 \mathrm{~V}$ (larger than that of commercial batteries for powering low power consumption electronics). In addition, the AMSCs show excellent cycle stability up to 10000 cycles.

\section{Experimental Section}

\subsection{Synthesis of the $\mathrm{Mo}_{1.33} \mathrm{C}$ MXene}

$\mathrm{Mo}_{1.33} \mathrm{C}$ was synthesized by etching $\left(\mathrm{Mo}_{2 / 3} \mathrm{Sc}_{1 / 3}\right)_{2} \mathrm{AlC} i$-MAX phase with $\mathrm{HF}$ as previously reported [30]. Briefly, one gram of the ( $\left.\mathrm{Mo}_{2 / 3} \mathrm{Sc}_{1 / 3}\right)_{2} \mathrm{AlC} i$-MAX phase powder was added to $20 \mathrm{ml}$ $48 \% \mathrm{HF}$, stirring for $24 \mathrm{~h}$ at room temperature. After the reaction, the product was washed with deionized water. After washing, multilayer MXene was delaminated into single/few layer MXene by intercalating with $\mathrm{TBAOH} .10 \mathrm{~mL} 40 \% \mathrm{TBAOH}$ water solution was added to the multilayer 
MXene, which was shaken for manually for $5 \mathrm{~min}$. Extra TBAOH was removed by centrifuging at 5000 r.p.m for $5 \mathrm{~min}$ and by (three times) carefully rinsing with water. Then, water was added to the intercalated powder and the mixture shaken for $5 \mathrm{~min}$, for delamination into single- or fewlayered MXene. Finally, homogeneous delaminated $\mathrm{Mo}_{1.33} \mathrm{C}$ MXene was obtained by centrifuging for $30 \mathrm{~min}$ at 3500 r.p.m.

\subsection{Synthesis of the $\mathrm{Ti}_{3} \mathrm{C}_{2} T_{x}$ MXene}

$\mathrm{Ti}_{3} \mathrm{C}_{2} \mathrm{~T}_{\mathrm{x}}$ was synthesized by etching $\mathrm{Ti}_{3} \mathrm{AlC}_{2} \mathrm{MAX}$ phase with $\mathrm{LiF} / \mathrm{HCl}$ as previously reported [56]. Briefly, $\mathrm{LiF}(1 \mathrm{~g})$ and $\mathrm{HCl}(20 \mathrm{~mL}, 9 \mathrm{M})$ were mixed by stirring in a Teflon vessel. Then, $\mathrm{Ti}_{3} \mathrm{AlC}_{2}$ powder $(1 \mathrm{~g})$ was slowly added into the mixture and were kept for $24 \mathrm{~h}$ at $35{ }^{\circ} \mathrm{C}$ under stirring. After the reaction, the product was repeatedly washed with deionized water and centrifuged at $3500 \mathrm{rpm}$ for 5 min. Finally, the homogeneous delaminated $\mathrm{Ti}_{3} \mathrm{C}_{2} \mathrm{~T}_{\mathrm{x}}$ supernatant was obtained by sonicating under Ar flow and followed by centrifugation for $1 \mathrm{~h}$ at $3500 \mathrm{rpm}$.

\subsection{Fabrication of electrochemical polymerization films on patterned substrate}

First, the patterned conductive substrate was made by photolithography. After cleaning with acetone, ethanol, and deionized water, the patterned conductive substrate was immersed in different forms of mixed solution. The electrochemical polymerization was then carried out in a three-electrode configuration, where the platinum sheet and $\mathrm{Ag} / \mathrm{AgCl}$ in $1 \mathrm{M} \mathrm{KCl}$ serve as the counter electrode and reference electrode, respectively. The E-M was obtained in $20 \mathrm{ml}$ aqueous solution containing $2 \mathrm{mg} \mathrm{Mo} \mathrm{M}_{1.33} \mathrm{C}$ and $20 \mu \mathrm{EDOT}$ monomer under constant voltage of $1.1 \mathrm{~V}$ and keep for $30 \mathrm{~min}$. For Py-M, in $20 \mathrm{ml}$ aqueous solution containing $2 \mathrm{mg} \mathrm{Mo}{ }_{1.33} \mathrm{C}$ and $20 \mu \mathrm{l}$ Pyrrole monomer under constant voltage of $1.0 \mathrm{~V}$ for $30 \mathrm{~min}$. For $\mathrm{E}-\mathrm{T}$ and Py-T, the same conditions were used, only replacing $\mathrm{Mo}_{1.33} \mathrm{C}$ with $\mathrm{Ti}_{3} \mathrm{C}_{2} \mathrm{~T}_{\mathrm{x}}$. For comparison, the PEDOT was synthesized by using an electrolyte of $0.1 \mathrm{M} \mathrm{Na}_{2} \mathrm{SO}_{4}$ under constant voltage of $1.1 \mathrm{~V}$ for $30 \mathrm{~min}$. The PPy was 
synthesized by using the electrolyte of $0.1 \mathrm{M}$ SDBS under constant voltage of $0.8 \mathrm{~V}$ for $100 \mathrm{~s}$. The $\mathrm{MnO}_{2}$ was grown in an aqueous solution containing $0.2 \mathrm{M} \mathrm{Mn}\left(\mathrm{CH}_{3} \mathrm{COO}\right)_{2} \bullet 4 \mathrm{H}_{2} \mathrm{O}$ and $0.2 \mathrm{M}$ $\mathrm{Na}_{2} \mathrm{SO}_{4}$ using constant voltage of $1.0 \mathrm{~V}$. After electrochemical polymerization, the as-fabricated films were rinsed in deionized water several times.

\subsection{Fabrication of the Flexible Solid-State AMSCs}

AMSCs were fabricated through the assembly of an E-M film and a $\mathrm{MnO}_{2}$ film by selective electrodeposition with a solid-state $\mathrm{PVA} / \mathrm{LiCl}$ electrolyte. First, $1 \mathrm{~g} \mathrm{LiCl}$ was mixed with $10 \mathrm{~mL}$ of deionized water, and $1 \mathrm{~g}$ of PVA was added. The whole mixture was stirred under $85^{\circ} \mathrm{C}$ until the mixture becomes clear. Then, the solution was kept at $85^{\circ} \mathrm{C}$ without stirring. Second, the gel electrolyte was carefully casted on the interdigital pattern area and left in air for $1 \mathrm{~h}$ at room temperature to evaporate excess water.

\subsection{Materials- and electrochemical characterization}

The electrochemical tests are performed using a VSP potentiostat (Bio-Logic, France). The impedance measurements are performed with a $5 \mathrm{mV}$ amplitude in a frequency range from 100 $\mathrm{mHz}$ to $100 \mathrm{kHz}$ at open-circuit potential. The morphology and microstructure of the different electrodes were investigated by means of field emission scanning electron microscopy (LEO 1550 Gemini) equipped with energy dispersive spectroscopy (EDS). XPS measurements were performed using monochromatic Al-Ka $(1,486.6 \mathrm{eV})$ radiation in a Kratos AXIS Ultra DLD system and a Scienta SES200 system. Transmission electron microscopy was performed in the

Linköping double corrected FEI Titan ${ }^{3} 60-300$, operated at $300 \mathrm{kV}$. The samples for TEM were prepared by dispersion of fine particles onto Holey-Carbon TEM grids.

\section{Results and Discussion}




\subsection{Polymer-MXene composite films formed by MXene-facilitated electrochemical polymerization}

In this work, to demonstrate the electrochemical polymerization of organic monomers enabled by 2D MXene without use of conventional electrolytes, the $\mathrm{Mo}_{1.33} \mathrm{C}$ MXene was mixed with EDOT in an aqueous solution. The electrochemical behavior of the EDOT and Mo1.33 C MXene mixture $(\mathrm{E}-\mathrm{M})$ was investigated by cyclic voltammetry $(\mathrm{CV})$ as shown in Figure 1B. From the $\mathrm{CV}$ in the potential sweep between -0.1 and $1.0 \mathrm{~V}$, two broad redox peaks were observed which are similar to those of EDOT in $\mathrm{Na}_{2} \mathrm{SO}_{4}$ electrolyte solution (E-N) (Figure $\mathrm{S} 1$ ). In the successive cycles the peak current increased, indicating coupling between the EDOT radical cations and the growth of the film on the electrode $[13,35,36]$. We cannot, however, form a polymer film in EDOT aqueous solution without MXene/conventional electrolyte (Figure S1B). Interestingly, EDOT with the $\mathrm{Mo}_{1.33} \mathrm{C}$ MXene can be oxidized at relatively lower potentials $\left(\mathrm{E}_{\text {onset }}=0.76 \mathrm{~V}\right.$ vs. $\left.\mathrm{Ag} / \mathrm{AgCl}\right)$ compared to the EDOT with $\mathrm{Na}_{2} \mathrm{SO}_{4}$ electrolyte $\left(\mathrm{E}_{\text {onset }}=0.89 \mathrm{~V} v s . \mathrm{Ag} / \mathrm{AgCl}\right)$. This is due to the anomalous surface charges and edge defects of MXenes. In addition, we found a thicker PEDOT EP film could be more easily prepared in MXene solution than in $\mathrm{Na}_{2} \mathrm{SO}_{4}$ electrolyte. This indicates that $\mathrm{Mo}_{1.33} \mathrm{C}$ MXene can more effectively facilitate the polymerization of EDOT.

To demonstrate the universality of the MXene-facilitated electrochemical polymerization, we investigated $\mathrm{Mo}_{1.33} \mathrm{C}$ MXene with Pyrrole (P-M) and $\mathrm{Ti}_{3} \mathrm{C}_{2}$ MXene with EDOT (E-T) or pyrrole (P-T). In all cases, the composite films were successfully deposited on the electrode. The CV curves for $\mathrm{Mo}_{1.33} \mathrm{C}$ MXene with Pyrrole and $\mathrm{Ti}_{3} \mathrm{C}_{2}$ MXene with EDOT or pyrrole are shown in Figure S1, together with PEDOT prepared in $\mathrm{Na}_{2} \mathrm{SO}_{4}$ electrolyte and PPy prepared in SDBS electrolyte (P-S) for comparison. In addition, the zeta potential of the MXene solution was not significantly changed by the addition of organic monomers, which means that the mixed colloidal solution can maintain a good stability (Table S1 and Figure S2). 
Conventional electrolytes are very important components for providing an electrically conductive environment and doped into the polymer film as counter ions during electrochemical polymerization. Generally, electrochemical polymerization cannot take place without the participation of electrolytes. Differently with common electrochemical polymerization, the method we demonstrate here could be schematically illustrated in Figure 1C. First, negatively charged MXene $\left(\mathrm{Ti}_{3} \mathrm{C}_{2}, \mathrm{Mo}_{1.33} \mathrm{C}\right)$ provided an electrolyte-like conductive environment in a stable dispersion mixed solution with organic monomers (Pyrrole, EDOT). Then, in the process of electrochemical polymerization, the organic monomers would lose electrons to an electrode form cationic radicals, which couple to each other and form polymer chains. Meanwhile, the negatively charged MXene would moves toward the working electrode driven by an electric field and doped into the polymer chains with a high content to form a complex film in the cationic radical coupling process. The composites with a conductive polymer as a host penetrated by MXene not only possess higher conductivity than the pristine polymer film (Figure S3,4), but also greatly improve the electrochemical performance of the conductive polymer film as shown in Figure S5-11.

Scanning electron microscopy (SEM) images of the four films (E-N, E-M, P-S, P-M) are shown in Figure 2 and Figure S12-14. The SEM micrographs show the change in morphology corresponding to different solution components. The PEDOT prepared in $\mathrm{Na}_{2} \mathrm{SO}_{4}$ electrolyte was uniformly coated onto the substrate with a random nanoflake morphology (Figure S12A). The electrodeposited PEDOT with $\mathrm{Mo}_{1.33} \mathrm{C}$ shows a nanosphere-shaped architecture (Figure 2A). For pyrrole, the morphology changed from a closely packed nanorod structure (Figure S12B) prepared from SDBS electrolyte to a nanosphere-shaped structure (Figure 2B) prepared from $\mathrm{Mo}_{1.33} \mathrm{C}$. The 3D structure of the E-M and P-M electrodes were further analyzed using cross-sectional SEM (Figure 2C, D). Both E-M and P-M shows a 3D porous structure composed of nanospheres (Figure 
S15). To further investigate the structure of the polymer-MXene composite, aberration corrected transmission electron microscopy (TEM) was applied. Figure 2E, F shows overview (inset) and high-resolution images of the E-M and P-M, respectively. The overview of the E-M structure identifies a particle with rounded features, similar to the particles observed by SEM. The corresponding high-resolution image of the particle edge shows bundles of parallel lines running along the outline of the particle edge. Each line can be interpreted as a single sheet of MXene (thickness about $1.1 \mathrm{~nm}$, Figure S16). These lines form loops, which suggests that few layer thick MXene form closed, approximately spherical shells that enclose the PEDOT (as schematic in Figure 1A). Correspondingly, the polymer-MXene composite overview shows a structure that locally forms spherical particles, though the majority of the structure appears as sheets. The highresolution image additionally identifies few-layer MXene closed loops. However, the structure is typically flatter and with smaller dimensions compared to the MXene/PEDOT shells. The MXene shells in the vicinity of the local spherical particles are composed of thicker (multiple) MXene layers.

The X-ray photoelectron spectroscopy (XPS) data shown in Figure 3A-C (see also Figure S17) confirm the incorporation of $\mathrm{Mo}_{1.33} \mathrm{C}$ MXene into the polymer films during the electrochemical polymerization. In addition, energy dispersive X-ray spectroscopy (EDX) elemental mapping was used to study the distribution of polymer-MXene (Figure 3D,E). EDX mapping of Mo confirms a homogeneous distribution of $\mathrm{Mo}_{1.33} \mathrm{C}$ MXene throughout the 3D polymer framework (see also Figure S18). The corresponding polymers of EDOT and Pyrrole prepared in MXene solution were confirmed by Fourier Transform Infrared Spectrometer (FT-IR) and absorption spectra (Figure S19 and 20). Based on the above results, we conclude that we have successfully obtained a 
polymer-MXene composite with a 3D porous structure by in situ electrodeposition in a solution of organic monomers (EDOT, Pyrrole) and MXenes.

\subsection{Electrochemical performance of polymer-MXene composite films}

For energy storage, nanosphere structures with plenty of pores will be beneficial for the infiltration and diffusion of the electrolyte, thus likely improving the capacitance. In addition, the nanosphere structure will help to resolve potential stagnant ion transport, which is one of the main challenges for pseudocapacitive materials [37-39]. Moreover, the dopant of MXene will further improve the conductivity and capacitance of the polymers (Figure S3,4). Steps for fabricating inplane solid state MSCs by in situ EP on a predesigned patterned substrate are shown in Figure S5. First, a piece of ITO was selectively etched to form a pattern of predesigned interdigitated electrodes by photolithography. Note that this method can be applied to any conductive substrate to prepare a variety of patterned electrodes. Subsequently, polymer-MXene MSCs were fabricated through a facile in situ electrochemical polymerization process. The electrochemical performance of the E-M and P-M MSCs were investigated in a two-electrode configuration. MSCs based on E$\mathrm{N}$ and P-S were examined for comparison. Cyclic voltammograms (CVs), at a scan rate of $50 \mathrm{mV}$ $\mathrm{s}^{-1}$, of the four polymer-based MSCs are shown in Figure $4 \mathrm{~A}$ and B. Typical rectangle-like CV curves were obtained for all of them. The CV curves of all MSCs devices at different scan rates are shown in Figure S6-11. The electrode material prepared in MXenes solution have much higher areal capacitance compared to the polymer prepared in conventional electrolytes. This could be attributed to the high-capacitance MXene, as well as the 3D porous structure that increase the accessibility of the active electrode materials, thus increasing the capacitance. Typical CV curves of the E-M MSCs at different scan rates are shown in Figure 4C, exhibiting a good rectangular shapes up to $200 \mathrm{mV} \mathrm{s}^{-1}$, which indicates a low resistance and good reversibility. Isosceles triangle 
shaped charge-discharge curves indicate good reversibility of the E-M MSCs at different current densities, as shown in Figure 4D, which is in good agreement with the CV curves. In addition, the E-M MSCs shows better coulombic efficiency than E-N MSCs.

The areal capacitances at different current density for the four MSCs are shown in Figure 4E. The E-M MSCs exhibits an areal capacitance of $47.4 \mathrm{mF} \mathrm{cm}^{-2}$ at $0.2 \mathrm{~mA} \mathrm{~cm}{ }^{-2}$, maintaining 44.1 $\mathrm{mF} \mathrm{cm}{ }^{-2}$ at $4 \mathrm{~mA} \mathrm{~cm}^{-2}$, with only a 7\% decrease. For E-T MSCs (Figure S10), areal capacitance values as high as $40.0 \mathrm{mF} \mathrm{cm}^{-2}$ at a current density of $0.2 \mathrm{~mA} \mathrm{~cm}^{-2}$ are observed, with a good $89 \%$ capacitance retention at a high current density of $4 \mathrm{~mA} \mathrm{~cm}^{-2}$. In contrast, the E-N MSCs shows only a $4.1 \mathrm{mF} \mathrm{cm}^{-2}$ capacitance at $20 \mu \mathrm{A} \mathrm{cm}^{-2}$, which decreases to $0.48 \mathrm{mF} \mathrm{cm}^{-2}$ at $0.2 \mathrm{~mA} \mathrm{~cm}^{-2}$, with only a $12 \%$ retention. The increased capacitance and rate performance are also reflected in the pyrrole-based MSCs. The increased capacitance and excellent rate-capabilities based on the polymer-MXene MSCs are possibly attributed to the superior electrical conductivity of the polymer-MXene composite films and fast ion transport in the 3D nanopores structure formed from in situ EP in mixtures of organic monomers and MXene. During the electrochemical polymerization process, the MXene self-assembly into a nanosphere structure that can effectively promote the electron transfer between the polymer and the MXene. The high-conductivity MXene shell formed on the outer periphery of interconnected nanosphere structures further promotes electron transport inside the film (as inset of Figure 1A upper right), realizing high capacitance and excellent rate-capabilities, in stark contrast to the insulating PSS shells of the prototypical PEDOT:PSS conducting polymer films [40-41]. The electrochemical capacitive behavior of the four MSCs was further investigated by electrochemical impedance spectroscopy (EIS), as shown in Figure 4F. It can be seen that the complex plane plots of E-M MSCs and P-M MSCs show a larger slope, close to $90^{\circ}$, compared to E-N and P-S MSCs at low frequency, which indicates fast 
ion diffusion. At high frequency, see inset in Figure 4F, E-M shows a smaller charge-transport semicircle than that of E-N MSC. This is consistent with the result of in-situ conductivity measurements, where the conductivity of the composite film (E-M and P-M) is found to be higher than that of a pristine polymer film (E-N and P-S) (Figure S3).

\subsection{Electrochemical performance of asymmetric microsupercapacitor}

Among the various transition metal oxide materials, $\mathrm{MnO}_{2}$ has been used widely as an energy storage electrode material owing to its remarkable theoretical specific capacitance $\left(\sim 1375 \mathrm{~F} \mathrm{~g}^{-1}\right)$, and being environmentally friendly, earth-abundant, and of low cost $[38,42,43]$. Considering the high pseudocapacitance of the $\mathrm{MnO}_{2}$ electrode and the excellent rate-capabilities of the E-M electrode, a flexible solid-state asymmetric microsupercapacitor (AMSC) device was assembled by in situ EP using E-M as the negative electrode and $\mathrm{MnO}_{2}$ as the positive electrode, as schematically illustrated in Figure S5. Charge balance between the two electrodes was achieved by controlling the deposition time of $\mathrm{MnO}_{2}$ at the positive electrode and the thickness of the E-M film at the negative electrode (Figure 5A). Finally, an operating potential window of up to $1.6 \mathrm{~V}$ was achieved for the AMSCs, which should yield a high energy density, and is the widest voltage window reported to date for MXene-based supercapacitors [44]. In addition, the cell voltage of this AMSCs device can be tuned from 1.0 to $2.0 \mathrm{~V}$, as shown in Figure 5B. The performance of the all-solid-state AMSCs was investigated through $\mathrm{CV}$ curves at various scan rates under $1.6 \mathrm{~V}$. As shown in Figure 5C, the shape of the CV curves remains pseudorectangular even at very high scan rate of $1000 \mathrm{mV} \mathrm{s}^{-1}$, which indicates a low resistance and fast charge-discharge properties. Galvanostatic charge/discharge curves of the full device with different current density between 0.0 and 1.6 V are shown in Figure 5D. The linear slope and triangular shape indicate good reversibility of the charge/discharge process, which is consistent with the CV curves. The current density 
dependence of the capacitance of the AMSCs is shown in Figure 5E. A high areal capacitance of $69.5 \mathrm{mF} \mathrm{cm}^{-2}\left(636.9 \mathrm{~F} \mathrm{~cm}^{-3}\right)$ can be achieved at $0.5 \mathrm{~mA} \mathrm{~cm}^{-2}$. Similar to the results of E-M MSCs, the AMSCs device also demonstrates a remarkable rate capability with capacitance retention of $61 \%$ as the current density increases from 0.5 to $4 \mathrm{~mA} \mathrm{~cm}^{-2}$. Long cycle life is another important feature of commercially viable supercapacitors. Therefore, the cycling stability of the AMSCs was investigated by galvanostatic charge/discharge tests at a current of $1.5 \mathrm{~mA} \mathrm{~cm}^{-2}$ (Figure 5F). Indeed, the asymmetric supercapacitor is very stable as it maintains over $92 \%$ of its original capacity after 10000 charge/discharge cycles. The EIS of the AMSCs demonstrates a slight increase of the internal resistance and the microscopic appearance of the electrode materials has hardly changed after 10000 cycles (Figure S25,26).

In addition, the AMSCs shows exceptional electrochemical stability under different bending angles. No significant deviation of the CV curves was observed when the bending angle changed from $0^{\circ}$ to $180^{\circ}$, displaying excellent capacitance stability at different bending curvatures (Figure 6A). To meet the high voltage or capacitance requirements, supercapacitors are often put into a bank of cells connected together in series or in parallel. CV and GCD measurement (Figure 6B, C) shows that the discharge time of AMSCs connected in parallel is twice as long as that of a single one within the same voltage window of $1.6 \mathrm{~V}$. Meanwhile, the output voltage of two devices connected in series is doubled. These results suggest that the fabricated devices have good reproducibility and can be well managed for practical power applications. The achieved high specific capacitance, outstanding rate capability, and tunable voltage window in AMSCs will pave the way for polymer-MXene based supercapacitors for high-level energy and power applications. The volumetric energy and power densities of different types of MSCs, as well as a comparison with previously reported MSCs devices, are plotted in the Ragone plot as shown in Figure 6D. For 
AMSCs, a maximum energy density of $250.1 \mathrm{mWh} \mathrm{cm}^{-3}$ can be obtained at a specific power density of $1.87 \mathrm{~W} \mathrm{~cm}^{-3}$. Importantly, the energy density remains $138.4 \mathrm{mWh} \mathrm{cm}^{-3}$ at a high power density of $32.9 \mathrm{~W} \mathrm{~cm}^{-3}$. The good retention of the high energy density also occurs in the polymerMXene based MSCs. The E-M MSCs exhibits energy density values in the range of 18.7-20 $\mathrm{mWh}$ $\mathrm{cm}^{-3}$ with a corresponding power density in the range of $0.4-8.3 \mathrm{~W} \mathrm{~cm}^{-3}$. For P-M, the energy density changes from 5.9 to $11.6 \mathrm{mWh} \mathrm{cm}^{-3}$ with a power density in the range of $0.3-6.8 \mathrm{~W} \mathrm{~cm}^{-3}$. These values are better than MSCs based on other materials, including carbon materials (0.15-9 $\left.\mathrm{mWh} \mathrm{cm}{ }^{-3}\right)$ [45-49], transition metal oxides/hydroxides/carbides $\left(1-5 \mathrm{mWh} \mathrm{cm}^{-3}\right)$ [50-55] and conducting polymers (5-11 $\left.\mathrm{mWh} \mathrm{cm}^{-3}\right)$ [56-57] manufactured through various technologies.

\section{Conclusions}

In summary, we developed a simple, green, and scalable method for synthesizing high quality conjugated polymer-MXene composites by in situ EP from the mixture of organic monomers and MXene without additional electrolyte. Patterned composite films with microstructures can be achieved on any conductive substrates by one step in-situ polymerization and the film thickness can be controlled by manipulating the amount of applied current on the electrode. The MSCs based on the unique interconnected 3D porous structure composed of polymer-MXene composite nanospheres realize excellent pseudocapacitance $\left(47.4 \mathrm{mF} \mathrm{cm}^{-2}\right)$ and ultrahigh energy capability $\left(20.05 \mathrm{mWh} \mathrm{cm}^{-3}\right)$. The polymer-MXene composite structure also improves the stability and rate performance of the MSCs significantly. Furthermore, by constructing an AMSCs with $\mathrm{MnO}_{2}$, the operating voltage increases up to $1.6 \mathrm{~V}$, the areal capacitance achieved $69.5 \mathrm{mF} \mathrm{cm}^{-2}$ and energy density up to $250.1 \mathrm{mWh} \mathrm{cm}^{-3}$. Our study opens a new avenue for convenient fabrication of polymer-MXene composite materials by electrochemical polymerization with greatly enhanced electrochemical performance, unfolding exciting opportunities in a wide range of mobile power 
supply applications including micro-portable electronics, electromechanical systems, and nanorobots.

\section{Acknowledgements}

This work was financed by the Swedish Energy Agency (EM 42033-1), the Swedish Government Strategic Research Area in Material Science on Functional Materials at Linköping Univer-sity (Faculty Grant SFO-Mat-LiU No 200900971) and Swedish Research Council (201704123), the SSF Research Infrastruc-ture Fellow program no. RIF 14-0074 and the SSF Synergy pro-gram EM16-0004, and by the Knut and Alice Wallenberg (KAW) Foundation through a Fellowship Grant, a Project Grant (KAW 2015.0043), and for support of the electron mi-croscopy laboratory and the device physics lab in Linköping. Support from the NSFC Project (61774077), the Open Fund of the State Key Laboratory of Luminescent Materials and De-vices (2018-skllmd12) and the Fundamental Research Funds for the Central Universities are also acknowledged.

\section{References}

[1] S.R. Forrest, The path to ubiquitous and low-cost organic electronic appliances on plastic, Nature 428 (2004) 911-918.

[2] Y. Shi, L. Peng, Y. Ding, Y. Zhao, G.H. Yu, Nanostructured conductive polymers for advanced energy storage, Chem. Soc. Rev. 44 (2015) 6684-6696.

[3] C. Reese, M. Roberts, M-M. Ling, Z.N. Bao, Organic thin film transistors, Mater. Today 7 (2004) 20-27.

[4] R.J. Mortimer, Electrochromic materials. Chem. Soc. Rev. 26 (1997) 147-156.

[5] O. Bubnova, Z.U. Khan, A. Malti, S. Braun, M. Fahlman, M. Berggren, X. Crispinet, Optimization of the thermoelectric figure of merit in the conducting polymer poly $(3,4-$ ethylenedioxythiophene), Nat. Mater. 10 (2011) 429-433. 
[6] T. Nezakati, A. Seifalian, A. Tan, A.M. Seifalian, Conductive Polymers: Opportunities and Challenges in Biomedical Applications, Chem. Rev. 118 (2018) 6766-6843.

[7] P.P. Deshpande, N.G. Jadhav, V.J. Gelling, D. Sazou, Conducting polymers for corrosion protection: a review. J. Coat. Technol. Res. 11 (2014) 473-494.

[8] J.H. Burroughes, D.D.C. Bradley, A.R. Brown, R.N. Marks, K. Mackay, R.H. Friend, P.L. Burns, A.B. Holmes, Light-emitting diodes based on conjugated polymers, Nature 347 (1990) 539541.

[9] P. Simon, Y. Gogotsi, Materials for electrochemical capacitors, Nat. Mater. 7 (2008) 845-854.

[10] C. Meng, J. Maeng, S.W.M. John, P. P. Irazoqui, Ultrasmall Integrated 3D Micro Supercapacitors Solve Energy Storage for Miniature Devices, Adv. Energy. Mater. 4 (2014) 1301269.

[11] N. Kurra, M.K. Hota, H. N. Alshareef, Conducting polymer micro-supercapacitors for flexible energy storage and Ac line-filtering, Nano Energy 13 (2015) 500-508.

[12] L.Q. Qin, J.K. Xu, B.Y. Lu, Y. Lu, X.M. Duan, G.M. Nie, Synthesis and electrochromic properties of polyacrylate functionalized poly(3,4-ethylenedioxythiophene) network films, J. Mater. Chem. 22 (2012) 18345-18353.

[13] L.Q. Qin, Z.Q. Ding, M. Hanif, J.J. Xia, L.L. Liu, Y.Q. Mo, Z.Q. Xie, Y.G. Ma, Poly(3,4dioxythiophene) soft nano-network with a compatible ion transporting channel for improved electrochromic performance, Polym. Chem. 7 (2016) 6954-6963.

[14] J. Kim, J. You, E. Kim, Flexible Conductive Polymer Patterns from Vapor Polymerizable and Photo-Cross-Linkable EDOT, Macromolecules 43 (2010) 2322-232.

[15] Beaujuge, P. M.; Reynolds, J. R. Color control in pi-conjugated organic polymers for use in electrochromic devices, Chem Rev. 2010, 110, 268-320.

[16] C. Gu, N. Huang, Y.C. Chen, L.Q. Qin, H. Xu, S.T. Zhang, F.H. Li, Y.G. Ma, D.L. Jiang, piConjugated Microporous Polymer Films: Designed Synthesis, Conducting Properties, and Photoenergy Conversions, Angew. Chem. Int. Ed. 54 (2015) 13594-13598. 
[17] C. Gu, T. Fei, Y. Lv, T. Feng, S.F. Xue, D. Lu, Y.G. Ma, Color-stable White Electroluminescence Based on a Cross - linked Network Film Prepared by Electrochemical Copolymerization, Adv. Mater. 22 (2010) 2702-2705.

[18] L.Q. Qin, Y.N. Zhang, X.Y. Wu, L. Nian, Z.Q. Xie, L.L. Liu, Y.G. Ma, In Situ Electrochemical Synthesis and Deposition of Discotic Hexa -peri -hexabenzocoronen Molecules on Electrodes: Self-Assembled Structure, Redox Properties, and Application for Supercapacitor, Small 11 (2015) 3028-3034.

[19] C. Gu, Y.C. Chen, Z.B. Zhang, S.F. Xue, S.H. Sun, K. Zhang, C.M. Zhong, H.H. Zhang, Y.Y. Pan, Y. Lv, Y.Q. Yang, F.H. Li, S.B. Zhang, F. Huang, Y.G. Ma, Electrochemical Route to Fabricate Film-Like Conjugated Microporous Polymers and Application for Organic Electronics, Adv. Mater. 25 (2013) 3443-3448.

[20] C. Gu, T. Fei, L. Yao, Y. Lv, D. Lu, Y.G. Ma, Multilayer Polymer Stacking by In Situ Electrochemical Polymerization for Color-Stable White Electroluminescence, Adv. Mater. 23 (2011) 527-530.

[21] H.H. Zhang, Y.N. Zhang, C. Gu, Y.G. Ma, Electropolymerized Conjugated Microporous Poly(zinc-porphyrin) Films as Potential Electrode Materials in Supercapacitors, Adv. Energy. Mater. 5 (2015) 1402175.

[22] J.A. Bard, L.R. Faulkner, Electrochemical Methods: Fundamentals and Applications John Wiley \& Sons, 2000

[23] M. Naguib, M. Kurtoglu, V. Presser, J. Lu, J.J. Niu, M. Heon, L. Hultman, Y. Gogotsi, M.W. Barsoum, Two-Dimensional Nanocrystals Produced by Exfoliation of $\mathrm{Ti}_{3} \mathrm{AlC}_{2}$, Adv. Mater. 23 (2011) 4248-4253.

[24] M.W. Barsoum, MAX Phases: Properties of Machinable Ternary Carbides and Nitrides John Wiley \& Sons, 2013. 
[25] M. Naguib, O. Mashtalir, J. Carle, V. Presser, J. Lu, L. Hultman, Y. Gogotsi, M.W.Barsoum, Two-Dimensional Transition Metal Carbides, ACS Nano 6 (2012) 1322-1331.

[26] M. Naguib, J. Halim, J. Lu, K.M. Cook, L. Hultman, Y. Gogotsi, M.W. Barsoum, New TwoDimensional Niobium and Vanadium Carbides as Promising Materials for Li-Ion Batteries, J. Am. Chem. Soc. 135 (2013) 15966-15969.

[27] J. Halim, K.M. Cook, M. Naguib, P. Eklund, Y. Gogotsi, J. Rosen, M.W. Barsoum, X-ray photoelectron spectroscopy of select multi-layered transition metal carbides (MXenes), Appl. Surf. Sci. 362 (2016) 406-417.

[28] M. Ghidiu, M.R. Lukatskaya, M-Q. Zhao, Y. Gogotsi, M.W. Barsoum, Conductive twodimensional titanium carbide 'clay' with high volumetric capacitance, Nature 516 (2014) 78-81.

[29] M. Dahlqvist, J. Lu, R. Meshkian, Q.Z. Tao, L. Hultman, J. Rosen, Prediction and synthesis of a family of atomic laminate phases with Kagomé-like and in-plane chemical ordering, Sci. Adv. 3 (2017) e1700642.

[30] Q.Z. Tao, M. Dahlqvist, J. Lu, S. Kota, R. Meshkian, J. Halim, J. Palisaitis, L. Hultman, M.W. Barsoum, P.O.Å. Persson, J. Rosen, Two-dimensional $\mathrm{Mo}_{1.33} \mathrm{C}$ MXene with divacancy ordering prepared from parent 3D laminate with in-plane chemical ordering, Nat. Commun. 8 (2017) 14949.

[31] L.Q. Qin, Q.Z. Tao, A.E. Ghazaly, J. Fernandez-Rodriguez, P.O.Å. Persson, J. Rosen, F.L. Zhang, High-Performance Ultrathin Flexible Solid-State Supercapacitors Based on Solution Processable Mo1.33C MXene and PEDOT:PSS, Adv. Fun. Mater. 28 (2018) 1703808.

[32] M. Boota, B. Anasori, C. Voigt, M-Q. Zhao, M.W. Barsoum, Y. Gogotsi, Pseudocapacitive Electrodes Produced by Oxidant-Free Polymerization of Pyrrole between the Layers of 2D Titanium Carbide (MXene), Adv. Mater. 28 (2016) 1517-1522.

[33] C. Chen, M. Boota, X.Q. Xie, M.Q. Zhao, B. Anasori, C.E. Ren, L. Miao, J.J. Jiang, Y. Gogotsi, Charge Transfer Induced Polymerization of EDOT Confined Between 2D Titanium Carbide Layers, J. Mater. Chem. A 5 (2017) 5260-5265.

[34] M. Zhu, Y. Huang, Q.H. Deng, J. Zhou, Z.X. Pei, Q. Xue, Y. Huang, Z.F. Wang, H.F. Li, Q. Huang, C.Y. Zhi, Highly Flexible, Freestanding Supercapacitor Electrode with Enhanced 
Performance Obtained by Hybridizing Polypyrrole Chains with MXene, Adv. Energy Mater. 6 (2016) 1600969.

[35] A. Ryosuke, A. Mahito, F. Toshio, Electropolymerization of an Immiscible Monomer in Aqueous Electrolytes Using Acoustic Emulsification, J. Am. Chem. Soc. 127 (2015) 13160-13161.

[36] Y. Lv, L. Yao, C. Gu, Y.X. Xu, D.D. Liu, D. Lu, Y.G. Ma, Electroactive Self-Assembled Monolayers for Enhanced Efficiency and Stability of Electropolymerized Luminescent Films and Devices, Adv. Funct. Mater. 21 (2011) 2896-2900.

[37] B.L. Ellis, P. Knauth, T. Djenizian, Three-Dimensional Self-Supported Metal Oxides for Advanced Energy Storage, Adv. Mater. 26 (2014) 3368-3397.

[38] X.Y. Lang, A. Hirata, T. Fujita, M.W. Chen, Nanoporous metal/oxide hybrid electrodes for electrochemical supercapacitors, Nat. Nanotechnol. 6 (2011) 232-236.

[39] J.H. Han, Y.C. Lin, L.Y. Chen, Y.C. Tsai, Y. Ito, X.W. Guo, A. Hirata, T. Fujita, M. Esashi, T. Gessner, M.W. Chen, On-Chip Micro-Pseudocapacitors for Ultrahigh Energy and Power Delivery, Adv. Sci. 2 (2015) 1500067.

[40] S.K.M. Jönsson, J. Birgerson, X. Crispin, G. Greczynski, W. Osikowicz, A.W.D. Gon, W.R. Salaneck, M. Fahlman, The effects of solvents on the morphology and sheet resistance in poly(3,4ethylenedioxythiophene)-polystyrenesulfonic acid (PEDOT-PSS) films, Synthetic Met. 139 (2003) $1-10$.

[41] G. Greczynski, T. Kugler, M. Keil, W. Osikowicz, M. Fahlman, W.R. Salanecka, Photoelectron spectroscopy of thin films of PEDOT-PSS conjugated polymer blend: a minireview and some new results, J. Electron Spec. Rel. Phenom. 121 (2001) 1-17.

[42] M.F. El-Kady, M. Ihns, M.P. Li, J.Y. Hwang, M.F. Mousavi, L. Chaney, A.T. Lech, R.B. Kaner. Engineering three-dimensional hybrid supercapacitors and microsupercapacitors for highperformance integrated energy storage, PANS 112 (2015) 4233-4238. 
[43] K.Q. Qin, J.L. Kang, J.J. Li, C.S. Shi, Y.X. Li, Z.J. Qiao, N.Q. Zhao, Free-Standing Porous Carbon Nanofiber/Ultrathin Graphite Hybrid for Flexible Solid-State Supercapacitors, ACS Nano 9 (2015) 481-487.

[44] Q. Jiang, N. Kurra, M. Alhabeb, Y. Gogotsi, H.N. Alshareef, All Pseudocapacitive MXeneRuO2 Asymmetric Supercapacitors, Adv. Energy Mater. (2018) 1703043.

[45] Z.-S. Wu, K. Parvez, X.L. Feng, K. Müllen, Graphene-based in-plane micro-supercapacitors with high power and energy densities, Nat. Commun. 4 (2013) 2487.

[46] Z.-S. Wu, K. Parvez, X.L. Feng, K. Müllen, Photolithographic fabrication of highperformance all-solid-state graphene-based planar micro-supercapacitors with different interdigital fingers, J. Mater. Chem. A 2 (2014) 8288-8293.

[47] Z.-S. Wu, Y.J. Zheng, S.H. Zheng, S.C. Wang, L. Sun, K. Parvez, T. Ikeda, X.H. Bao, K. Müllen, X.L. Feng, Stacked-Layer Heterostructure Films of 2D Thiophene Nanosheets and Graphene for High-Rate All-Solid-State Pseudocapacitors with Enhanced Volumetric Capacitance, Adv. Mater. 29 (2017) 1602960.

[48] W.W. Liu, C.X. Lu, X.L. Wang, R.Y. Tay, B.K. Tay, High-Performance Microsupercapacitors Based on Two-Dimensional Graphene/Manganese Dioxide/Silver Nanowire Ternary Hybrid Film, ACS Nano 9 (2015) 1528-1542.

[49] X. Pu, M.M. Liu, L.X. Li, S.C. Han, X.L. Li, C.Y. Jiang, C.H. Du, J.J. Luo, W.G. Hu, Z.L. Wang, Wearable Textile-Based In-Plane Microsupercapacitors, Adv. Energy Mater. (2016) 1601254.

[50] Y.J. Lin, Y. Gao, Z.Y. Fan, Printable Fabrication of Nanocoral-Structured Electrodes for High-Performance Flexible and Planar Supercapacitor with Artistic Design, Adv. Mater. (2017) 1701736.

[51] A.D. Dillon, M.J. Ghidiu, A.L. Krick, J. Griggs, S.J. May, Y. Gogotsi, M.W. Barsoum, A.T. Fafarman, Highly Conductive Optical Quality Solution-Processed Films of 2D Titanium Carbide, Adv. Funct. Mater. 26 (2016) 4162-4168. 
[52] Y-Y. Peng, B. Akuzum, N. Kurra, M-Q. Zhao, M. Alhabeb, B. Anasori, E.C. Kumbur, H.N. Alshareef, M-D. Gerc, Y. Gogotsi, All-MXene (2D titanium carbide) solid-state microsupercapacitors for on-chip energy storage, Energy Environ. Sci. 9 (2016) 2847-2854.

[53] N. Kurra, Q. Jiang, H.N. Alshareef, A general strategy for the fabrication of high performance microsupercapacitors, Nano Energy 16 (2015) 1-9.

[54] R.S. Guo, In-Plane Micro-Supercapacitors for an Integrated Device on One Piece of Paper, Adv. Funct. Mater. (2017) 1702394.

[55] N. Kurra, N.A. Alhebshi, H.N. Alshareef, Microfabricated Pseudocapacitors Using $\mathrm{Ni}(\mathrm{OH})_{2}$ Electrodes Exhibit Remarkable Volumetric Capacitance and Energy Density. Adv. Energy Mater. 5 (2015) 1401303.

[56] M.S. Zhu, Y. Huang, Y. Huang, H.F. Li, Z.F. Wang, Z.X. Pei, Q. Xue, H.Y. Geng, C.Y. Zhi, A Highly Durable, Transferable, and Substrate-Versatile High-Performance All-Polymer MicroSupercapacitor with Plug-and-Play Function, Adv. Mater. 29 (2017) 1605137.

[57] Q. Jiang, N. Kurra, H.N. Alshareef, Marker Pen Lithography for Flexible and Curvilinear OnChip Energy Storage, Adv. Funct. Mater. 25 (2015) 4976-4984. 
Figures and captions:

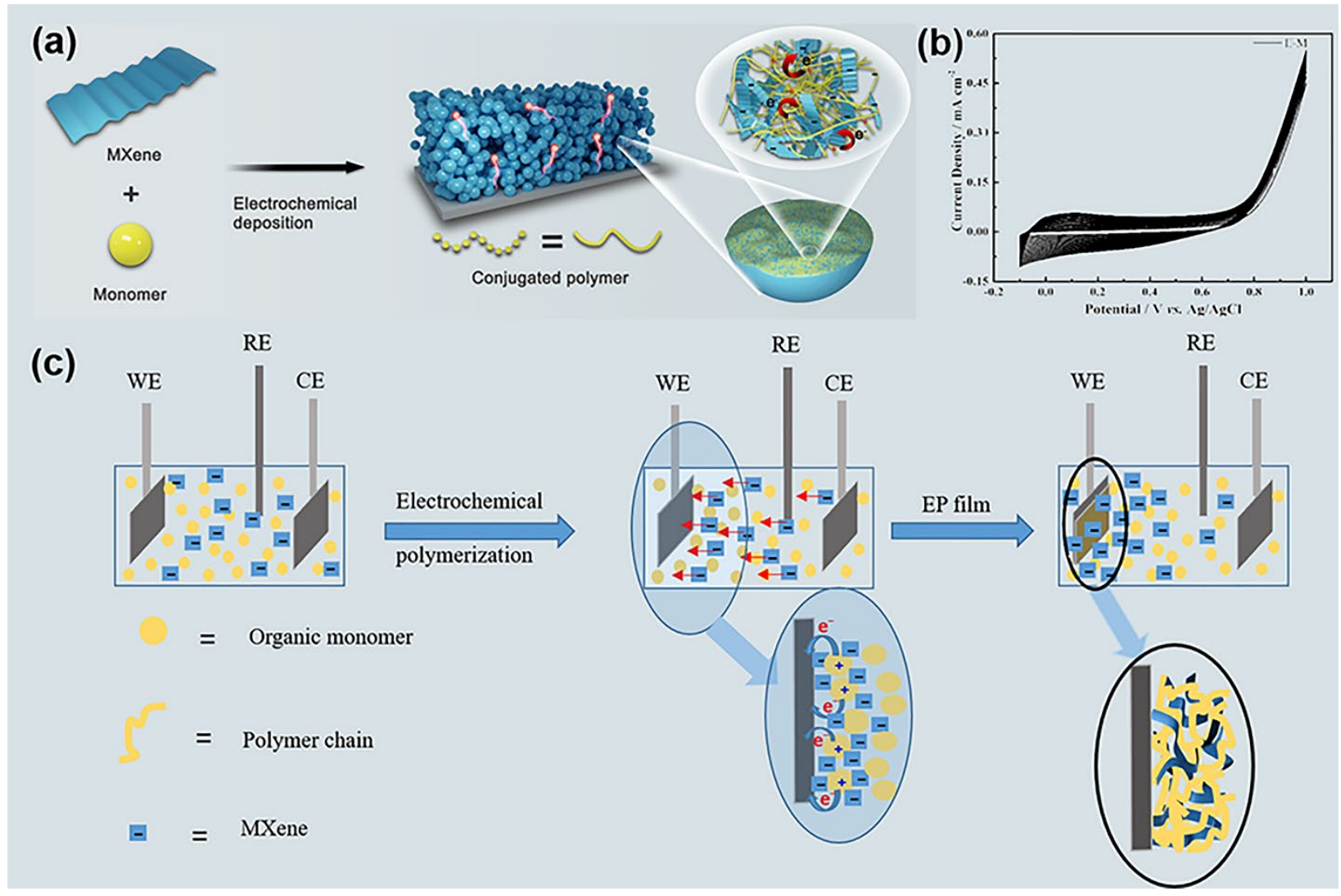

Figure 1. Schematic illustration. (a) The scheme for electrochemical polymerization of conjugated polymer-MXene composite nanospheres. (b) CV for the electrochemical polymerization of EDOT facilitated by MXene at the scan rate of $50 \mathrm{mV} \mathrm{s}^{-1}\left(0.1 \mathrm{mg} \mathrm{ml}^{-1} \mathrm{Mo}_{1.33} \mathrm{C}\right.$ and $1 \mu \mathrm{ml}^{-1}$ EDOT monomer in $\mathrm{H}_{2} \mathrm{O}$ ). (c) Schematic diagram of MXene-facilitated electrochemical polymerization mechanism. 

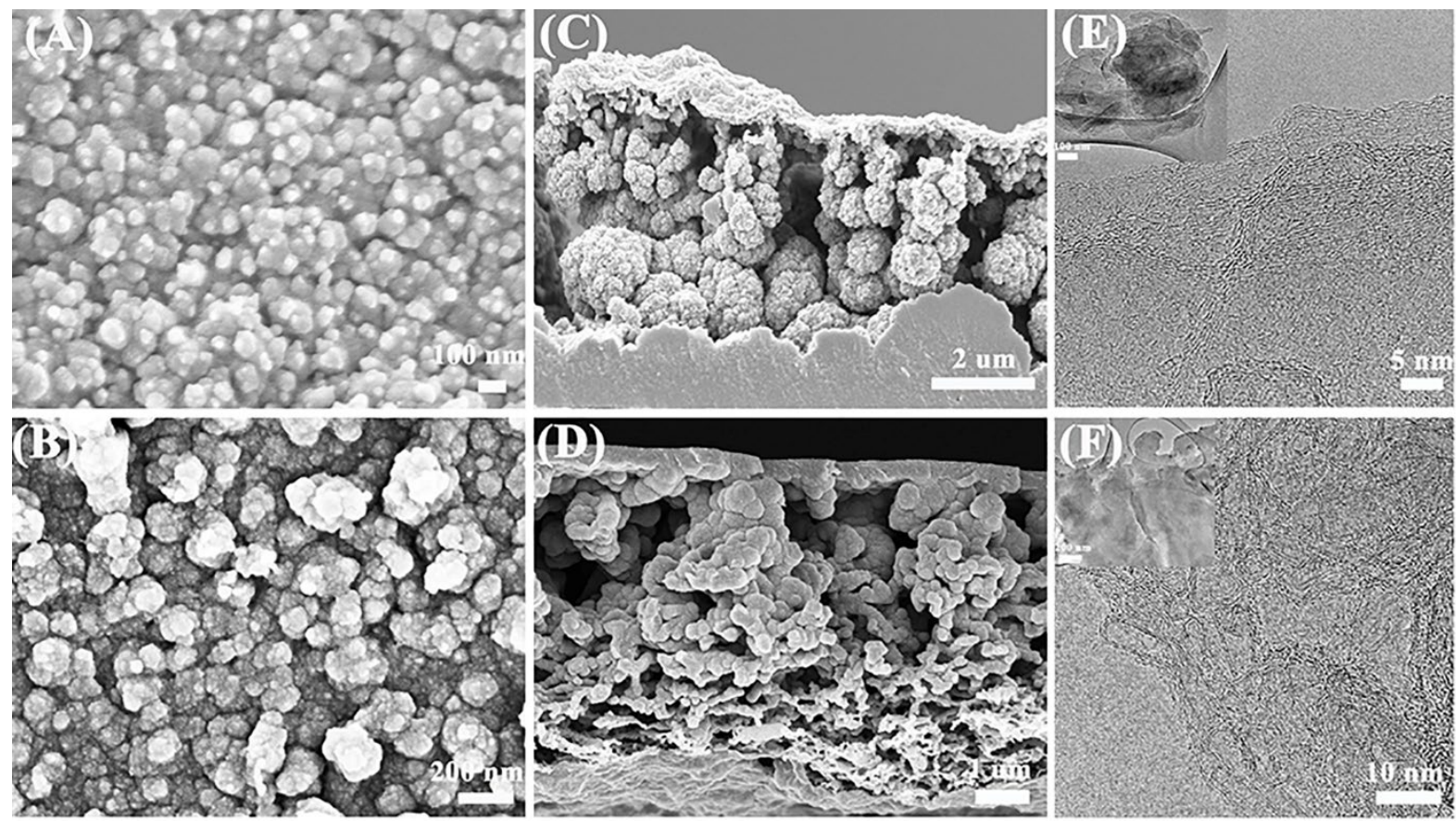

Figure 2. Morphology of conjugated polymer-MXene complex. SEM image of (A) PEDOT prepared in $\mathrm{Mo}_{1.33} \mathrm{C}(\mathrm{E}-\mathrm{M})$; (B) PPy prepared in $\mathrm{Mo}_{1.33} \mathrm{C}(\mathrm{P}-\mathrm{M})$; cross-sectional SEM image of $(\mathrm{C})$ E-M and (D) P-M; HRTEM image of E-M (E, inset: the overview image of E-M) and P-M (F, inset: the overview image of P-M). 


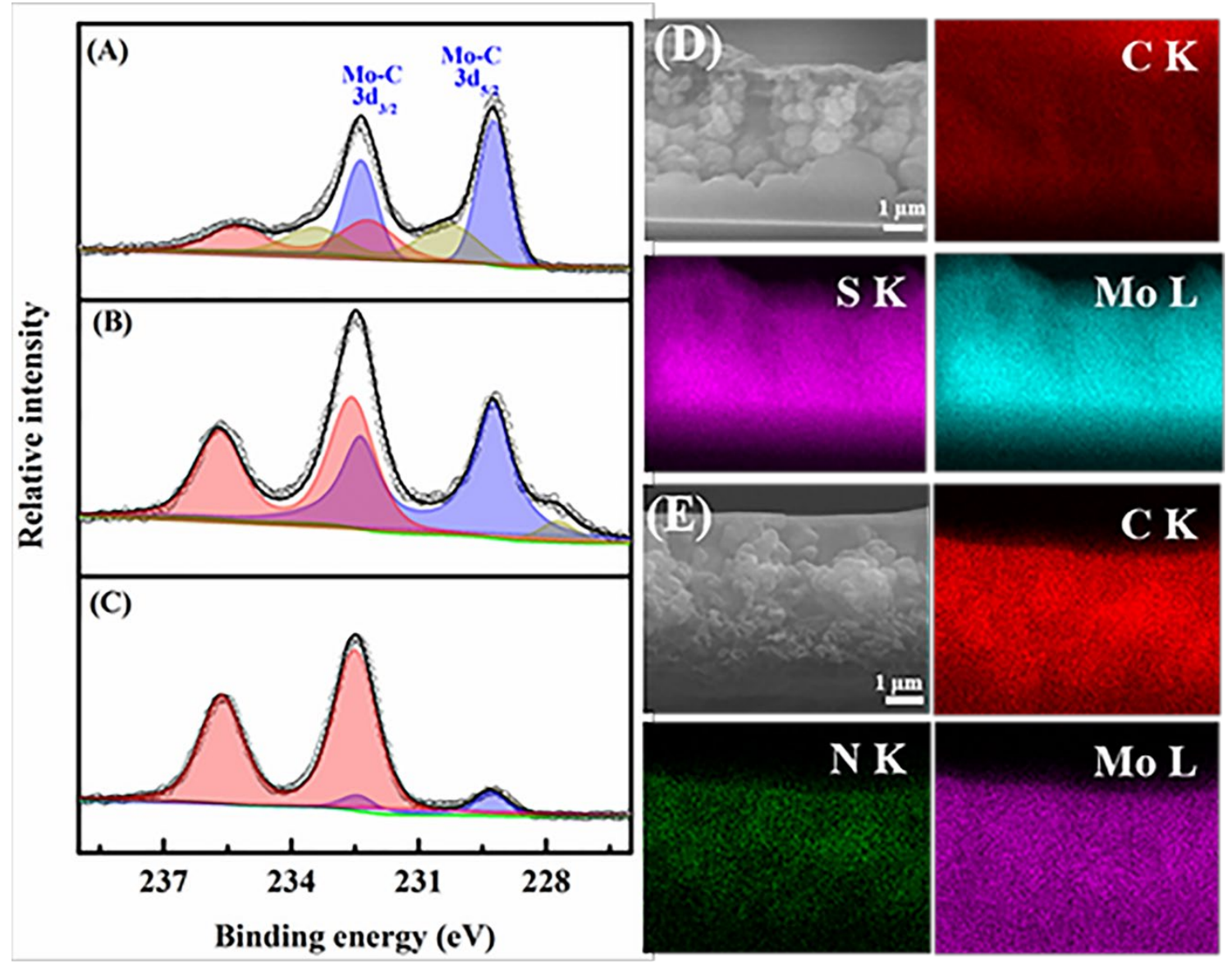

Figure 3. Distribution of MXene in complex. Mo 3d XPS spectra of (A) pristine $\mathrm{Mo}_{1.33} \mathrm{C},(\mathrm{B}) \mathrm{E}-$ $\mathrm{M}$ and (C) P-M; EDS elemental mapping of cross-sectional (D) E-M and (E) P-M. 

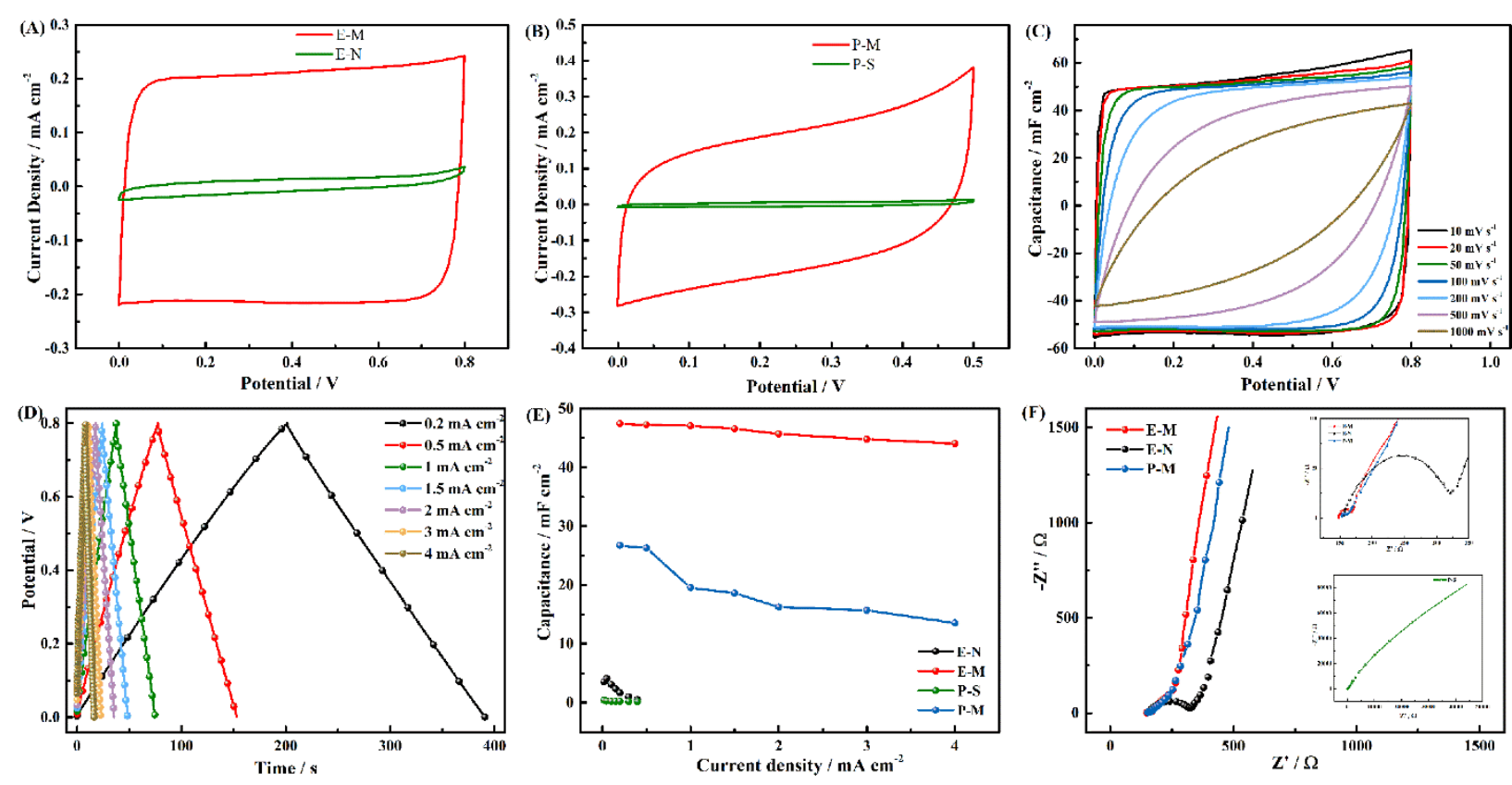

Figure 4. Electrochemical performance of microsupercapacitors. A) Comparison of CV curves of E-N MSCs and E-M MSCs tested under the scan rates of $50 \mathrm{mV} \mathrm{s}^{-1}, \mathrm{~B}$ ) Comparison of CV curves of P-S MSCs and P-M MSCs tested under the scan rates of $50 \mathrm{mV} \mathrm{s}^{-1}, \mathrm{C}$ ) Detailed CV curves of the E-M MSCs tested under different scan rates, D) Galvanostatic charging/discharging curves of the E-M MSCs with different current densities, E) Comparison of areal capacitances of E-N, E-M, P-S and P-M at different current density, F) Nyquist plot of the device tested at the open-circuit potential within the frequency range from $10^{-1}$ to $10^{5} \mathrm{~Hz}$. The above inset shows the enlarged plot in the high-frequency region. The following inset show the Nyquist plot of P-S. 

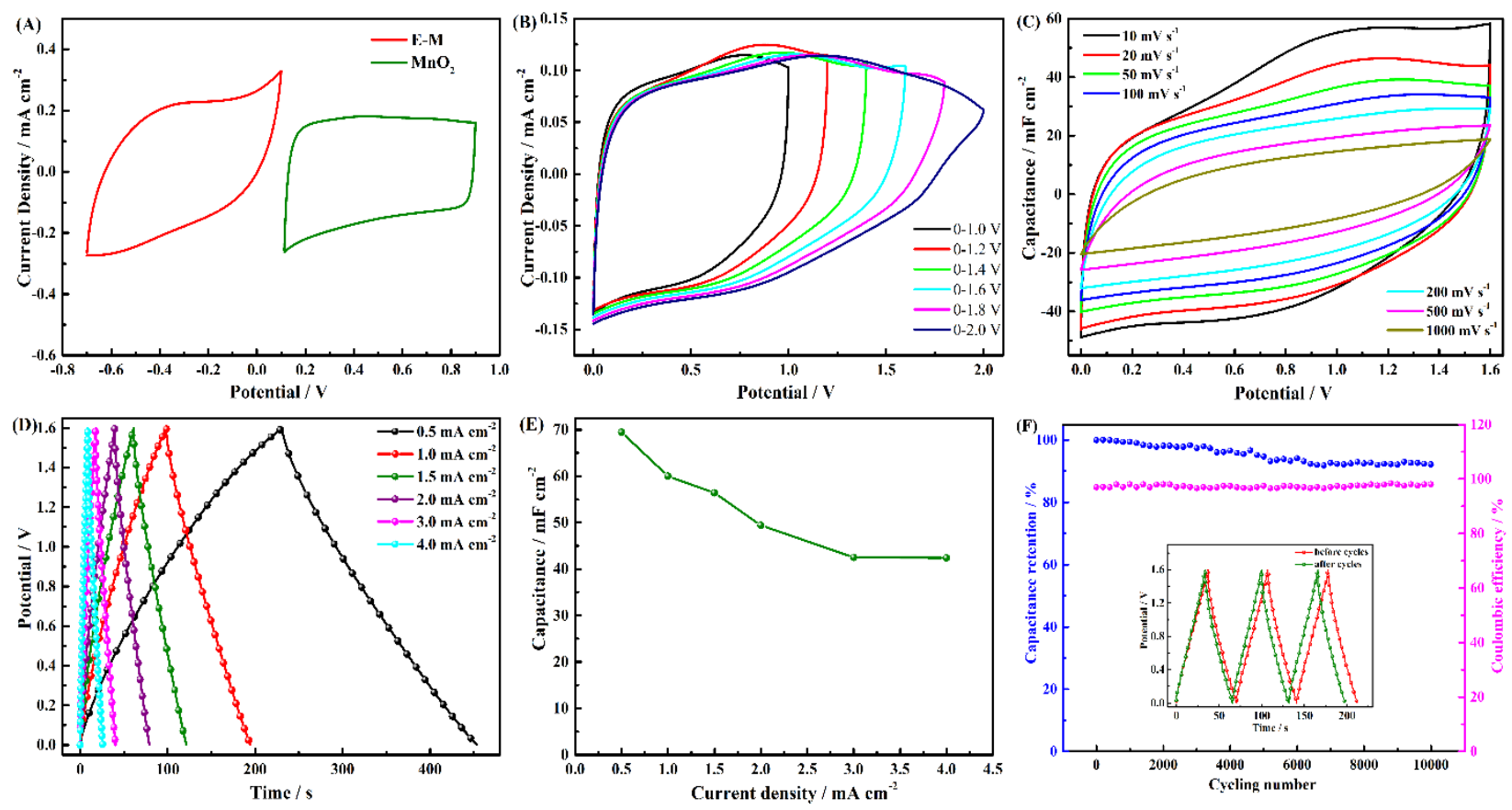

Figure 5. Performance of the asymmetric microsupercapacitors up to $1.6 \mathrm{~V}$. (A) Comparison of $\mathrm{CV}$ curves collected for E-M and $\mathrm{MnO}_{2}$ electrodes at a scan rate of $100 \mathrm{mV} \mathrm{s}^{-1}$. (B) CV curves of the AMSCs device collected at different voltage windows. (C) Areal specific capacitance of AMSCs device at different scan rate. (D) Galvanostatic charge/discharge curves of AMSCs at different current densities. (E) Areal specific capacitance of AMSCs at different current density. (F) Long-term charge-discharge cycling performance of the AMSCs device. Inset: Changes of galvanostatic charge/discharge curves of AMSCs device before and after 10000 cycles. 

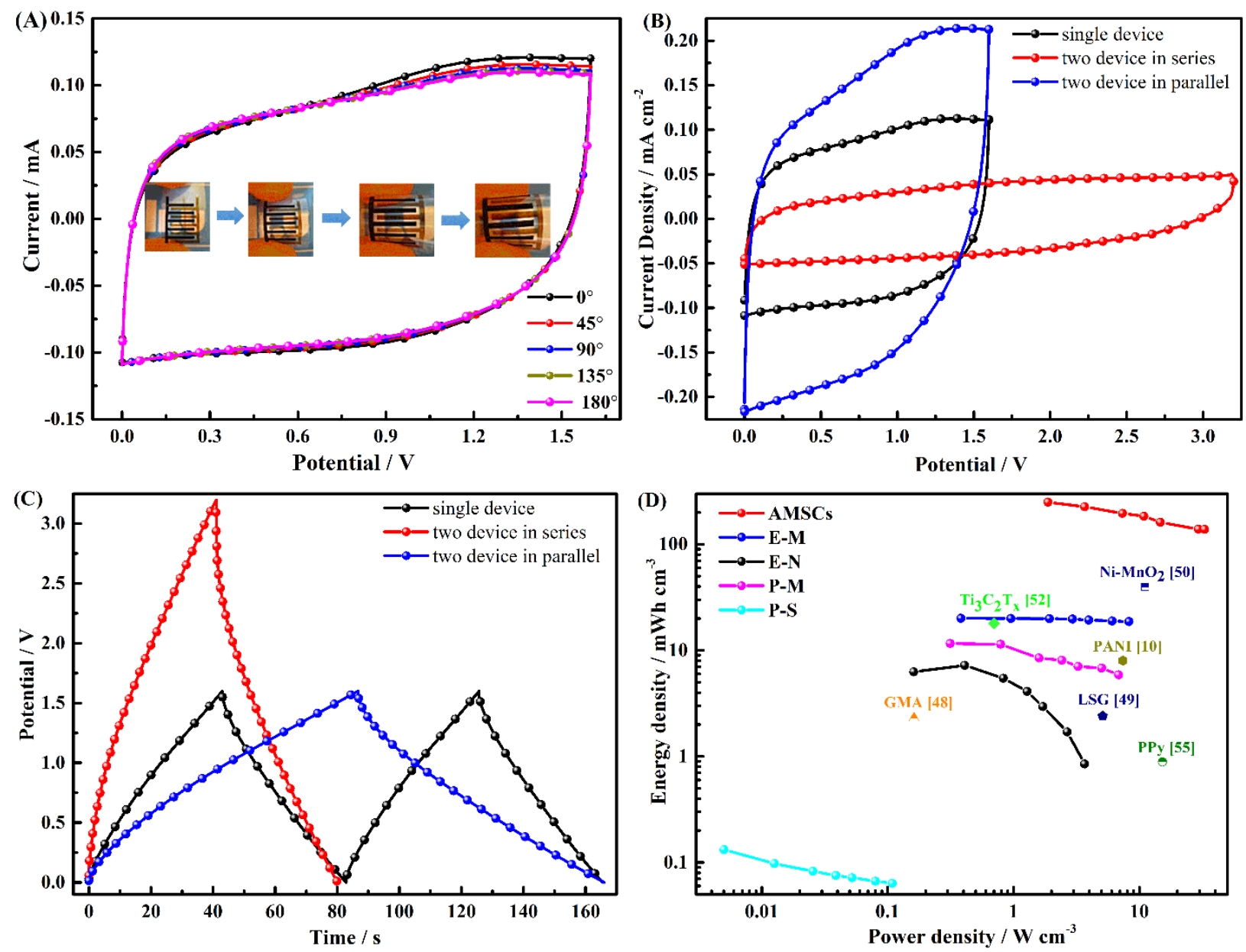

Figure 6. (A) CV curves of the AMSCs device bended with different angles at $100 \mathrm{mV} \mathrm{s}^{-1}$. Inset:

Optical image of the flexible AMSCs. (B) CV curves of AMSCs devices connected in series and in parallel at a scan rate of $100 \mathrm{mV} \mathrm{s}^{-1}$. A single device is shown for comparison. C) GCD curves of AMSCs devices connected in series and in parallel at a current density of $1 \mathrm{~mA} \mathrm{~cm}^{-2}$. (D) Energy and power density of the MSCs devices and AMSCs device compared with previously reported devices. 


\section{TOC Graphic}

Polymer-MXene Composite Films formed by MXene-facilitated Electrochemical Polymerization for Flexible Solid-State Microsupercapacitors

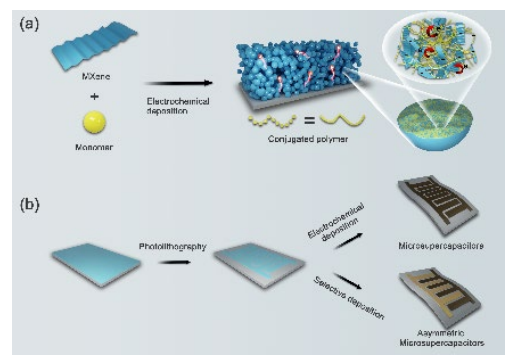

Keywords: MXene; electrochemical polymerization; conjugated polymer; composite film; microsupercapacitors 


\section{Supporting Information}

\section{Polymer-MXene Composite Films formed by MXene-facilitated Electrochemical Polymerization for Flexible Solid-State Microsupercapacitors}

Leiqiang Qin ${ }^{\mathrm{a}, *}$, Quanzheng Tao ${ }^{\mathrm{a}}$, Xianjie Liu ${ }^{\mathrm{a}}$, Mats Fahlman ${ }^{\mathrm{a}}$, Joseph Halim ${ }^{\mathrm{a}}$, Per O. Å. Persson $^{\mathrm{a}}$, Johanna Rosen ${ }^{\mathrm{a}, *}$, Fengling Zhang ${ }^{\mathrm{a}, \mathrm{b}, *}$

${ }^{\text {a} D e p a r t m e n t ~ o f ~ P h y s i c s, ~ C h e m i s t r y ~ a n d ~ B i o l o g y ~(I F M), ~ L i n k o ̈ p i n g ~ U n i v e r s i t y, ~ S E-581 ~} 83$ Linköping, Sweden.

${ }^{\mathrm{b}}$ Guangzhou Key Laboratory of Vacuum Coating Technologies and New Energy Materials, Physics Department, Jinan University, Guangzhou, 510632, P. R. China.

E-mail: leiqiang.qin@liu.se; johanna.rosen@liu.se; fengling.zhang@liu.se

Apparatuses. The electrochemical tests are performed using a VSP potentiostat (Bio-Logic, France). The impedance measurements are performed with a $5 \mathrm{mV}$ amplitude in a frequency range from $100 \mathrm{mHz}$ to $100 \mathrm{kHz}$ at open-circuit potential. The morphology and microstructure of the different electrodes were investigated by means of field emission scanning electron microscopy (LEO 1550 Gemini) equipped with energy dispersive spectroscopy (EDS). XPS measurements were performed using monochromatic Al-Ka $(1,486.6 \mathrm{eV})$ radiation in a Kratos AXIS U1tra DLD system and a Scienta SES200 system. Transmission electron microscopy was performed in the Linköping double corrected FEI Titan ${ }^{3} 60-300$, operated at $300 \mathrm{kV}$. The samples for TEM were prepared by dispersion of fine particles onto Holey-Carbon TEM grids. Spectroelectrochemical studies were carried out on a Cary 50 UV-vis-NIR spectrophotometer under computer control. The zeta potential were measurement by Malvern Zetasizer Nano ZS Analyzer. The samples were prepare by ultrasound to form a homogeneous dilute solution. Infrared spectra were recorded using a Bruker Vertex 70 Fourier transform infrared (FT-IR) spectrometer with samples in $\mathrm{KBr}$ pellets. Thermogravimetric analysis (TGA) was performed with a Pyris Diamond TG/DTA thermal analyzer (Perkin-Elmer) under a Argon stream at the heating rate of $10 \mathrm{~K} \mathrm{~min}^{-1}$. AFM was used to study the thickness of $\mathrm{Mo}_{1.33} \mathrm{C}$ films at ambient 
conditions (room temperature in a lab) using a Veeco DI Dimension 3100 scanning probe microscope, equipped with the Nanoscope IV electronics. The measurements were performed in tapping mode using Si tips (PPPNCHR-50 from Nanosensors) with a tip radius of curvature $<7 \mathrm{~nm}$. Nitrogen adsorption isotherms of E-M and P-M were measured at $77 \mathrm{~K}$ using an ASAP 2020 instrument (Micromeritics U.S.). The total surface area was calculated with the BET method, and the pore size distribution data were calculated using the BJH and DFT methods based on the adsorption and desorption data.

Calculations. The capacitance was calculated from the galvanostatic charge/discharge curves at different current densities using the formula using the following equation:

$$
C_{\text {device }}=\frac{i}{d E / d t}
$$

where $i$ is the current applied (in amps, A), and $d E / d t$ is the slope of the discharge curve (in volts per second, V/s). Specific capacitances were calculated based on the area and the volume of the device stack according to the following equations:

$$
\begin{aligned}
& C_{A}=\frac{C_{\text {device }}}{A} \\
& C_{v}=\frac{C_{\text {device }}}{V}
\end{aligned}
$$

where $\mathrm{C}_{A}$ is the areal capacitance in $\mathrm{mF} \mathrm{cm} \mathrm{cm}^{-2}, \mathrm{C}_{\mathrm{v}}$ is the volumetric capacitance in $\mathrm{F} \mathrm{cm}^{-3}$. A and $\mathrm{V}$ refer to the area $\left(\mathrm{cm}^{2}\right)$ and the volume $\left(\mathrm{cm}^{3}\right)$ of the active material on both electrodes, respectively.

The energy density of each device was obtained from the formula given in Equation (4):

$$
E=\frac{1000}{2 \times 3600} C_{v} \Delta E^{2}
$$


where $\mathrm{E}$ is the energy density in $\mathrm{Wh} \mathrm{cm}^{-3}, \mathrm{C}_{v}$ is the volumetric capacitance obtained from galvanostatic charge/discharge curves using Equation (3) in $\mathrm{F} \mathrm{cm}^{-3}$ and $\Delta E$ is the operating voltage window in volts.

The power density of each device was calculated using the equation:

$$
P=\frac{E}{t}
$$

where $P$ is the power density in $\mathrm{W} \mathrm{cm}^{-3}$ and $t$ is the discharge time in hours.

Asymmetric cells. In order to achieve optimal performance with asymmetric supercapacitors, there should be a charge balance between the positive and negative electrodes. The charge stored by each electrode depends on its volumetric capacitance $\left(\mathrm{C}_{v(\text { electrode })}\right)$, volume of the electrode $(\mathrm{V})$, and the potential window in which the material operates $(\Delta E)$.

$$
q=C_{v(\text { electrode })} \times V \times \Delta E
$$

To attain the charge balance, the following condition must be satisfied

$$
\begin{gathered}
q_{+}=q_{-} \\
\frac{V_{+}}{V_{-}}=\frac{\mathrm{C}_{v(\text { electrode })-} \times \Delta E_{-}}{C_{v(\text { electrode })+} \times \Delta E_{+}}
\end{gathered}
$$

\section{Electrochemical polymerization Behavior in Different Mixture Composition}



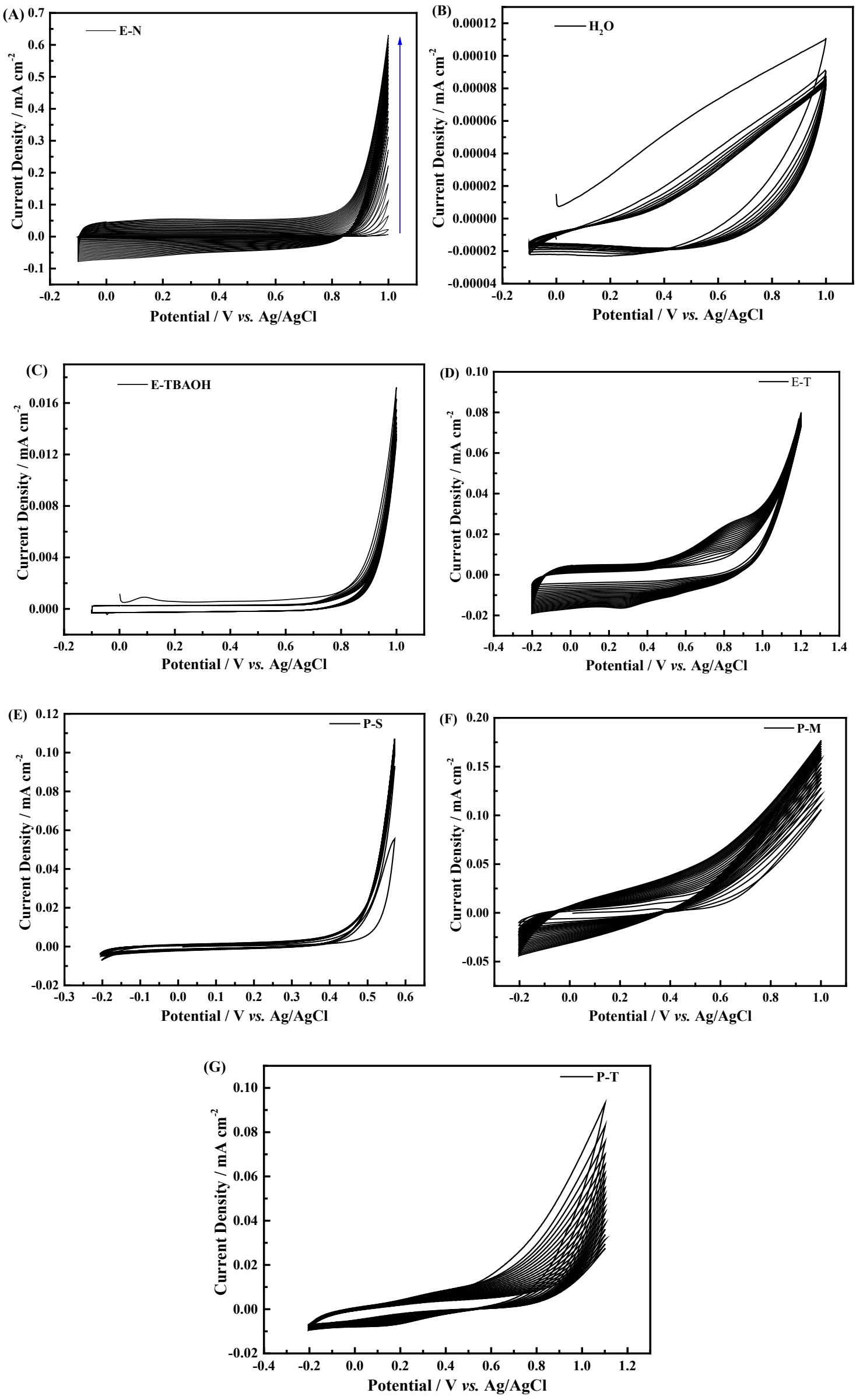
Figure S1. CV for the electrochemical polymerization of different mixture composition at the scan rate of $50 \mathrm{mV} \mathrm{s}^{-1}$. (A) $0.1 \mathrm{M} \mathrm{Na}_{2} \mathrm{SO}_{4}$ and $1 \mu \mathrm{ml}^{-1}$ EDOT monomer in $\mathrm{H}_{2} \mathrm{O}$, (B) $1 \mu \mathrm{ml}^{-1}$ EDOT monomer in $\mathrm{H}_{2} \mathrm{O}$, (C) $0.1 \mathrm{M}$ TBAOH and $1 \mu \mathrm{ml}^{-1}$ EDOT monomer in $\mathrm{H}_{2} \mathrm{O}$, (D) 0.1 $\mathrm{mg} \mathrm{ml}^{-1} \mathrm{Ti}_{3} \mathrm{C}_{2} \mathrm{~T}_{\mathrm{x}}$ and $1 \mu \mathrm{ml}^{-1}$ EDOT monomer in $\mathrm{H}_{2} \mathrm{O}$, (E) $0.1 \mathrm{M}$ SDBS and $1 \mu \mathrm{ml}^{-1}$ Pyrrole monomer in $\mathrm{H}_{2} \mathrm{O}$, (F) $0.1 \mathrm{mg} \mathrm{ml}^{-1} \mathrm{Mo}_{1.33} \mathrm{C}$ and $1 \mu \mathrm{ml}^{-1}$ Pyrrole monomer in $\mathrm{H}_{2} \mathrm{O}$, (G) $0.1 \mathrm{mg}$ $\mathrm{ml}^{-1} \mathrm{Ti}_{3} \mathrm{C}_{2} \mathrm{~T}_{\mathrm{x}}$ and $1 \mu 1 \mathrm{ml}^{-1}$ Pyrrole monomer in $\mathrm{H}_{2} \mathrm{O}$.

The electrochemical behavior of different mixture compositions was investigated by the cyclic voltammetry $(\mathrm{CV})$ method as shown in Figure S1. For EDOT with an electrolyte of $\mathrm{Na}_{2} \mathrm{SO}_{4}$, the representative current growth revealing the electrochemical performance of monomers and the formation of corresponding polymers is depcited in Figure S1A. The same electrochemical polymerization behavior also appears in EDOT with MXene $\left(\mathrm{Mo}_{1.33} \mathrm{C}\right.$ and $\left.\mathrm{Ti}_{3} \mathrm{C}_{2} \mathrm{~T}_{\mathrm{x}}\right)$ without electrolyte (Figure 1B and Figure S1D). In this case, we can successfully deposit EP films on the working electrode. This indicated that MXene can effectively promote the electrochemical polymerization of EDOT. To further demonstrate the function of MXene in electrochemical polymerization, the $\mathrm{CV}$ method was carried out for EDOT in aqueous solution without electrolyte or MXene, as shown in Figure S1B. The current is significantly reduced compared to electrolyte/MXene cases, and no obvious redox peaks or current growth follow the progress of CV. There also is no EP film observed on the working electrode. This indicates that the electrochemical polymerization of EDOT cannot be carried out in absence of an electrolyte. For $\mathrm{Mo}_{1.33} \mathrm{C}, \mathrm{TBAOH}$ was used during the intercalation. In order to exclude the impact of residual TBAOH, CV was carried out for EDOT with TBAOH, where the current growth or the EP film is not observed. We also demonstrate that polypyrrole can be obtained through EP of the monomer using MXene $\left(\mathrm{Mo}_{1.33} \mathrm{C}\right.$ and $\left.\mathrm{Ti}_{3} \mathrm{C}_{2}\right)$. The above result shows that MXene can effectively promote electrochemical polymerization, replacing conventional electrolytes.

\section{Zeta potential of the Different Mixture Composition}

Table S1. The Zeta potential of different sample.

\begin{tabular}{ccccccc}
\hline Sample & M & M-E & M-P & T & T-E & T-P \\
\hline $\begin{array}{c}\text { Zeta Potential } \\
(\mathrm{mV})\end{array}$ & -40.1 & -41.5 & -43.1 & -42.0 & -40.6 & -41.2 \\
\hline
\end{tabular}



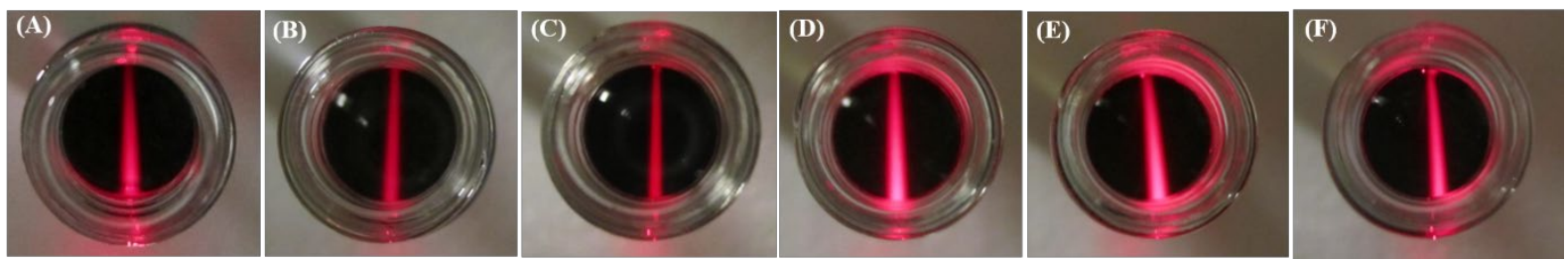

Figure S2. Digital photographs of the (A) Mo ${ }_{1.33} \mathrm{C}$, (B) Mo ${ }_{1.33} \mathrm{C}+\mathrm{EDOT}$, (C) Mo1.33 C+Pyrrole, (D) $\mathrm{Ti}_{3} \mathrm{C}_{2}$, (E) $\mathrm{Ti}_{3} \mathrm{C}_{2}+$ EDOT and $(\mathrm{F}) \mathrm{Ti}_{3} \mathrm{C}_{2}+$ Pyrrole colloids, all displaying a clear Tyndall scattering effect with laser light.

From the Table $\mathrm{S} 1$, the surfaces of the $\mathrm{Mo}_{1.33} \mathrm{C}$ and $\mathrm{Ti}_{3} \mathrm{C}_{2}$ sheets are both shown to be negatively charged with a zeta-potential of $-40.1 \mathrm{mV}$ and $-42.0 \mathrm{mV}$, respectively. A simple mixing of the MXene and organic monomers yields a homogeneous dispersion with no observation of apparent precipitation even after storing without stirring for weeks. The zeta potential of the MXene solution did not significantly change by mixing MXene with organic monomers, suggesting that the mixed colloidal solution can maintain good stability. Figure S2 shows the optical images of the obtained dispersions with the observation of a strong Tyndall scattering effect when directing a side-incident light beam on the colloidal dispersions. Delaminated nanosheets are responsible for this phenomenon.

\section{Electrical performance of sample}

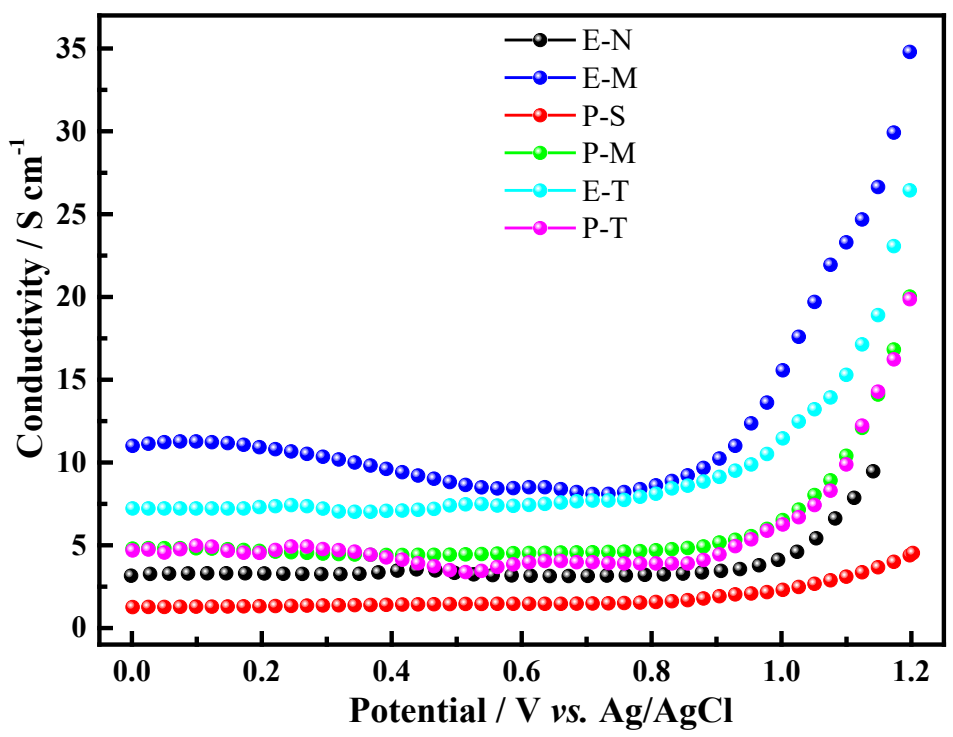

Figure S3. Conductance changes at different potentials for E-N, E-M, P-S, P-M, P-T and E-T. 
The in situ conductivity measurements has been carried out using a four-terminal setup. The microelectrochemical setup consists of two working interdigitated electrodes with an applied constant bias $(0.05 \mathrm{~V})$ connected by the EP film channel. $\mathrm{Ag} / \mathrm{AgCl}$ was used as reference electrode, while a Pt wire was used as the counter electrode and $0.1 \mathrm{M} \mathrm{LiCl}$ was electrolyte. Cyclic voltammetry measurements were performed by retaining a bias between the two working electrode of $0.05 \mathrm{~V}$. A constant bias $(\mathrm{E}=-0.05 \mathrm{~V})$ has been applied between the two working electrodes to produce a current flow in the channel, which dominates the observed voltammetric response. The recorded currents have then been divided by the applied bias, to produce a conductance $(\mathrm{C})$ response as function of the applied voltage (vs $\mathrm{Ag} / \mathrm{AgCl}$ ). Conductivity $(\sigma)$ has then been calculated as: $\sigma=\mathrm{C} \times \mathrm{L} / \mathrm{A}$, where $\mathrm{A}$ is the cross-sectional area and $\mathrm{L}$ is the channel length.
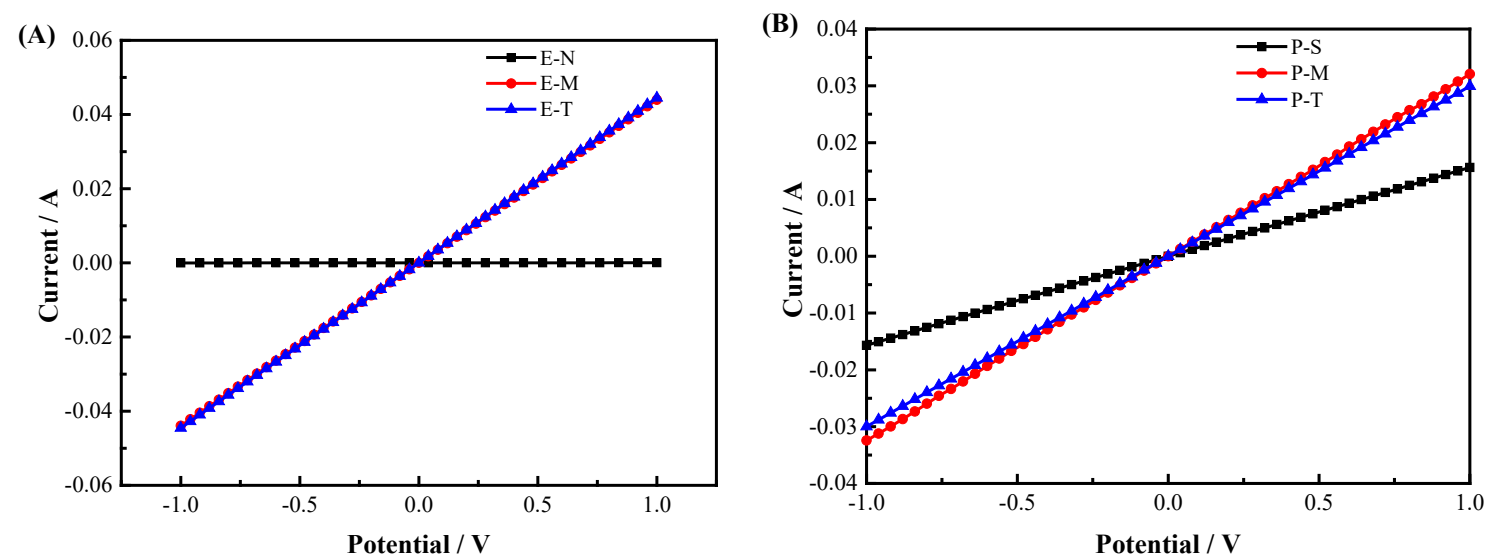

Figure S4. I-V curves of E-N, E-M, E-T, P-S, P-M, and P-T.

4. Electrochemical Performance of Symmetric Microsupercapacitors. 


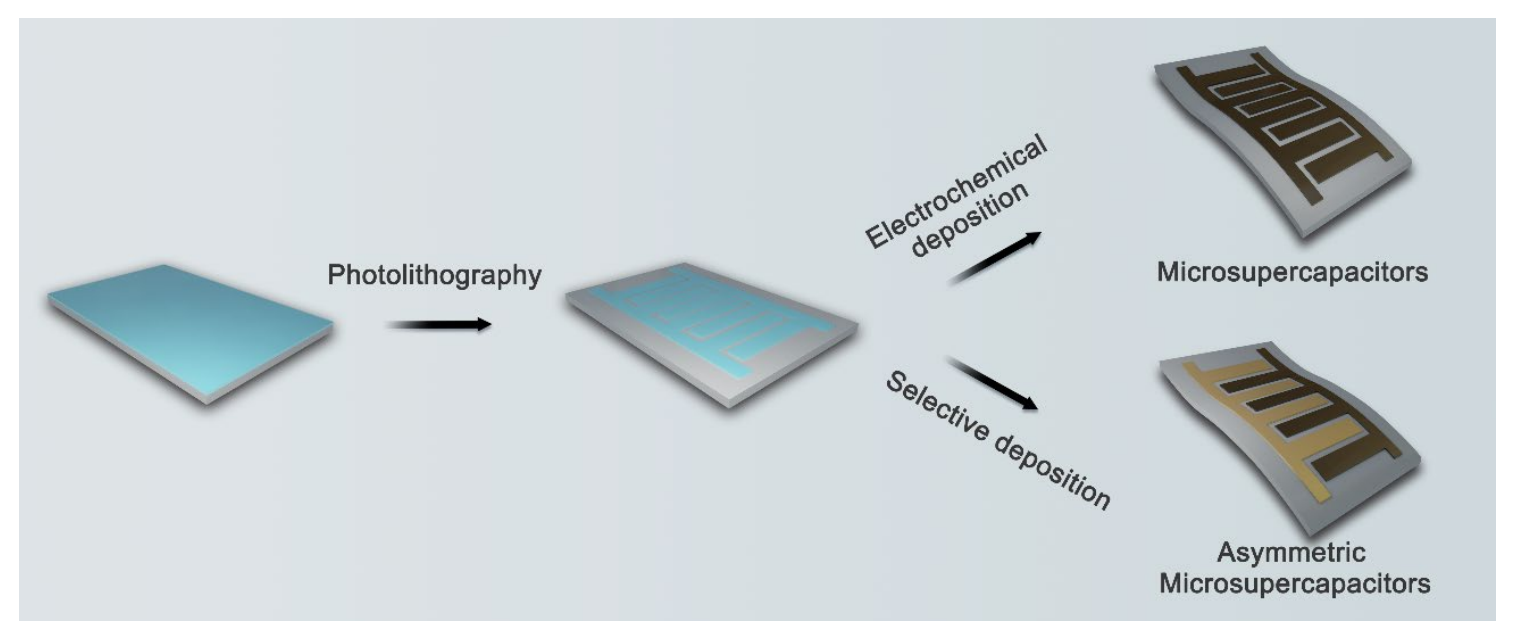

Figure S5. Schematic procedure for the fabrication of microsupercapacitors.
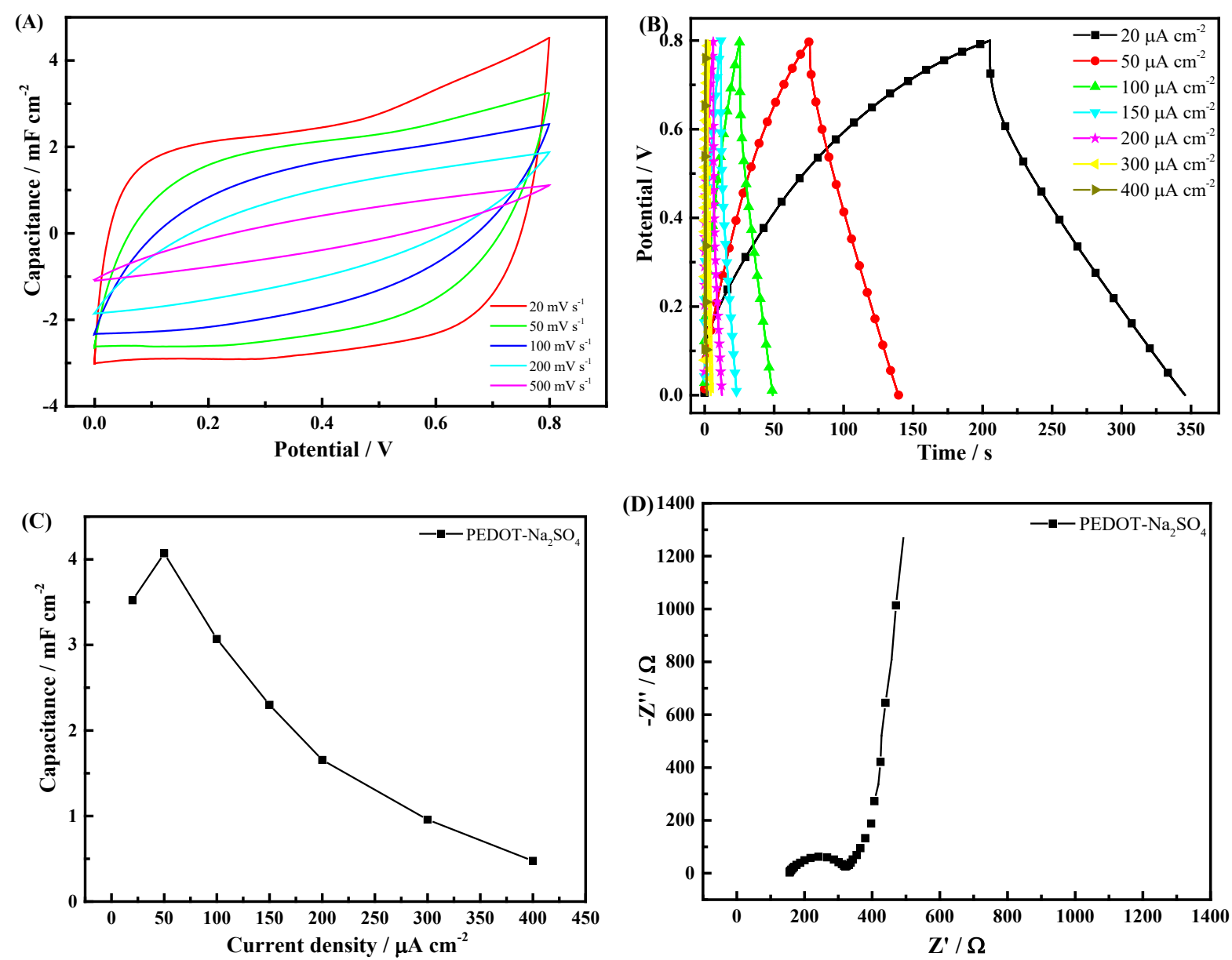

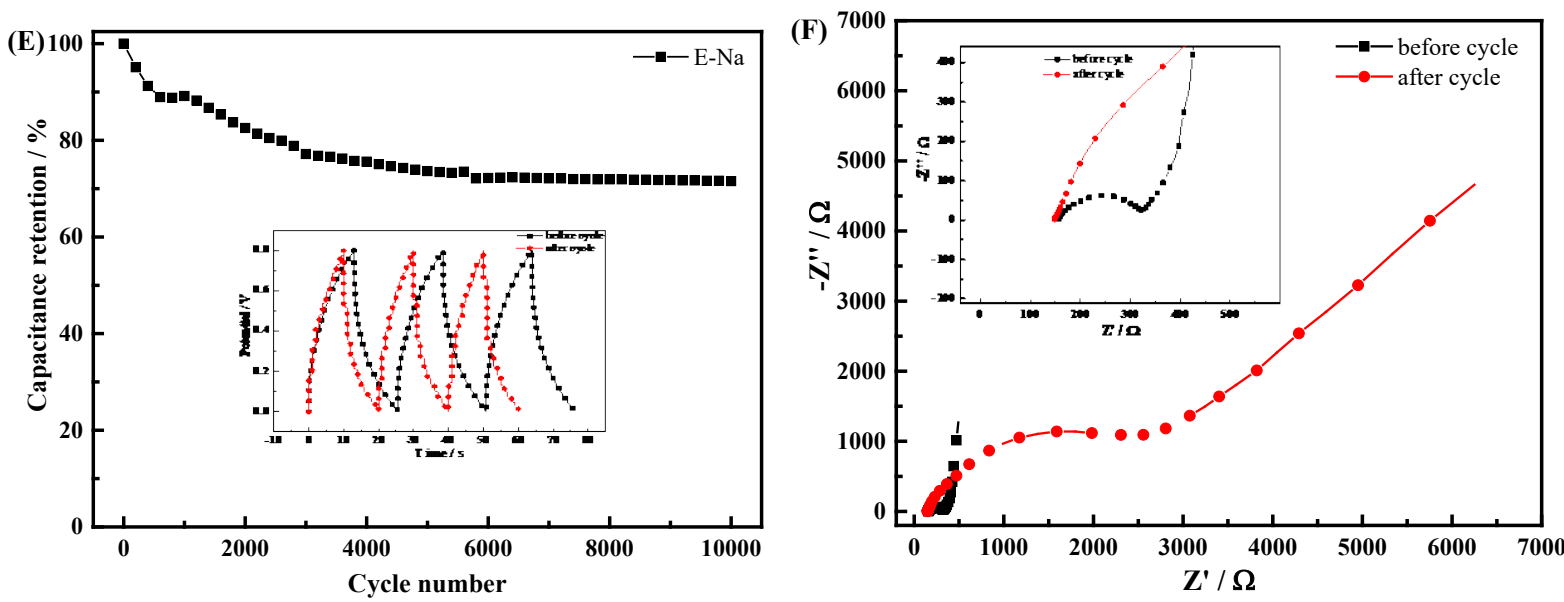

Figure S6. Electrochemical performance of E-Na symmetric Microsupercapacitors. (A) areal capacitance of E-Na MSCs at different scan rate. (B) Galvanostatic charge/discharge curves of E-Na MSCs at different current densities. (C) Rate performances of E-Na MSCs at different current density. (D) Electrochemical impedance spectroscopy data of E-Na MSCs tested at the open-circuit potential within the frequency range from $10^{-1}$ to $10^{5} \mathrm{~Hz}$. (E) Long-term chargedischarge cycling performance of the E-Na MSCs device. Inset: The comparison of GCD curves before and after cycling test. (F) The comparison of EIS spectra before and after cycling test. Inset: the enlarged plot in the high frequency region.
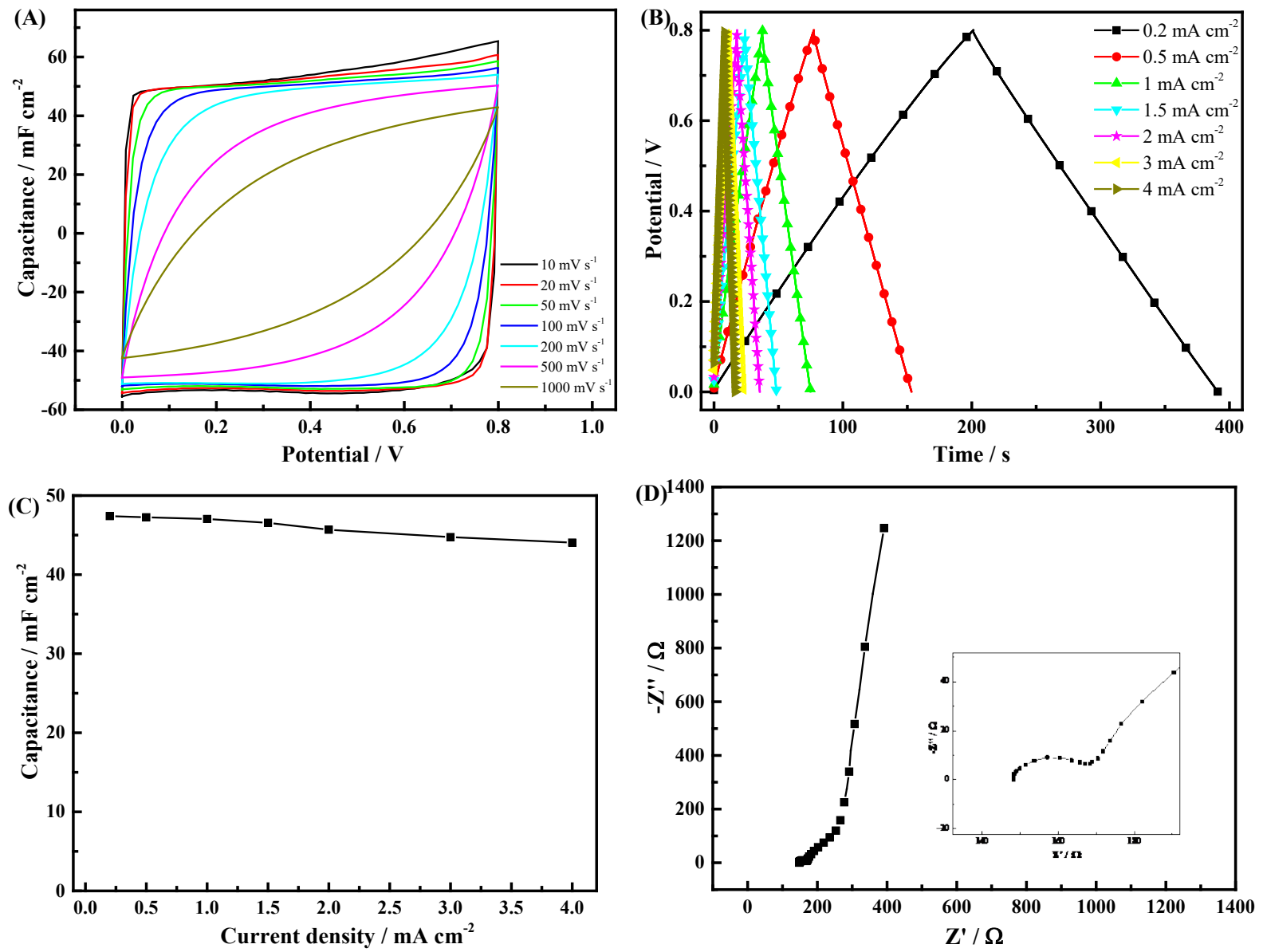

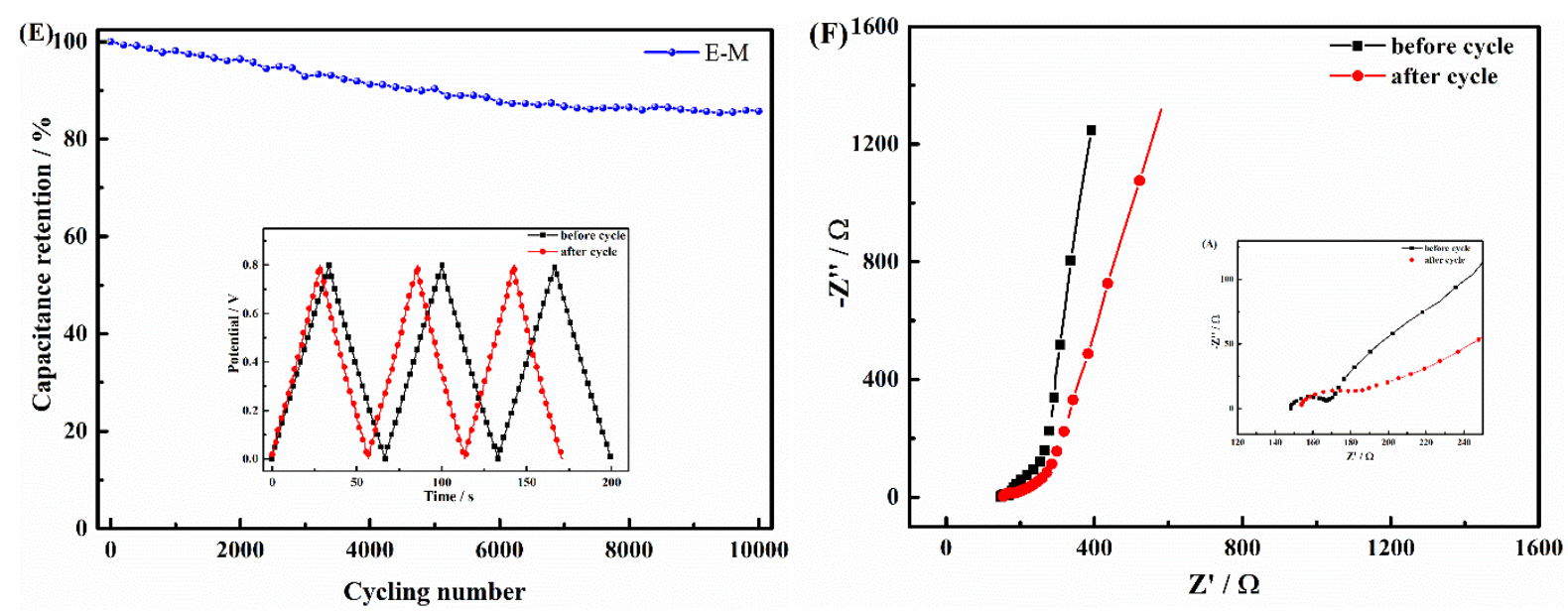

Figure S7. Electrochemical performance of E-M symmetric Microsupercapacitors. (A) areal capacitance of E-M MSCs at different scan rate. (B) Galvanostatic charge/discharge curves of E-M MSCs at different current densities. (C) Rate performances of E-M MSCs at different current density. (D) Electrochemical impedance spectroscopy data of E-M MSCs tested at the open-circuit potential within the frequency range from $10^{-1}$ to $10^{5} \mathrm{~Hz}$. The inset shows the enlarged plot in the high frequency region. (E) Long-term charge-discharge cycling performance of the E-M MSCs device. Inset: The comparison of GCD curves before and after cycling test. (F) The comparison of EIS spectra before and after cycling test. Inset: the enlarged plot in the high frequency region.
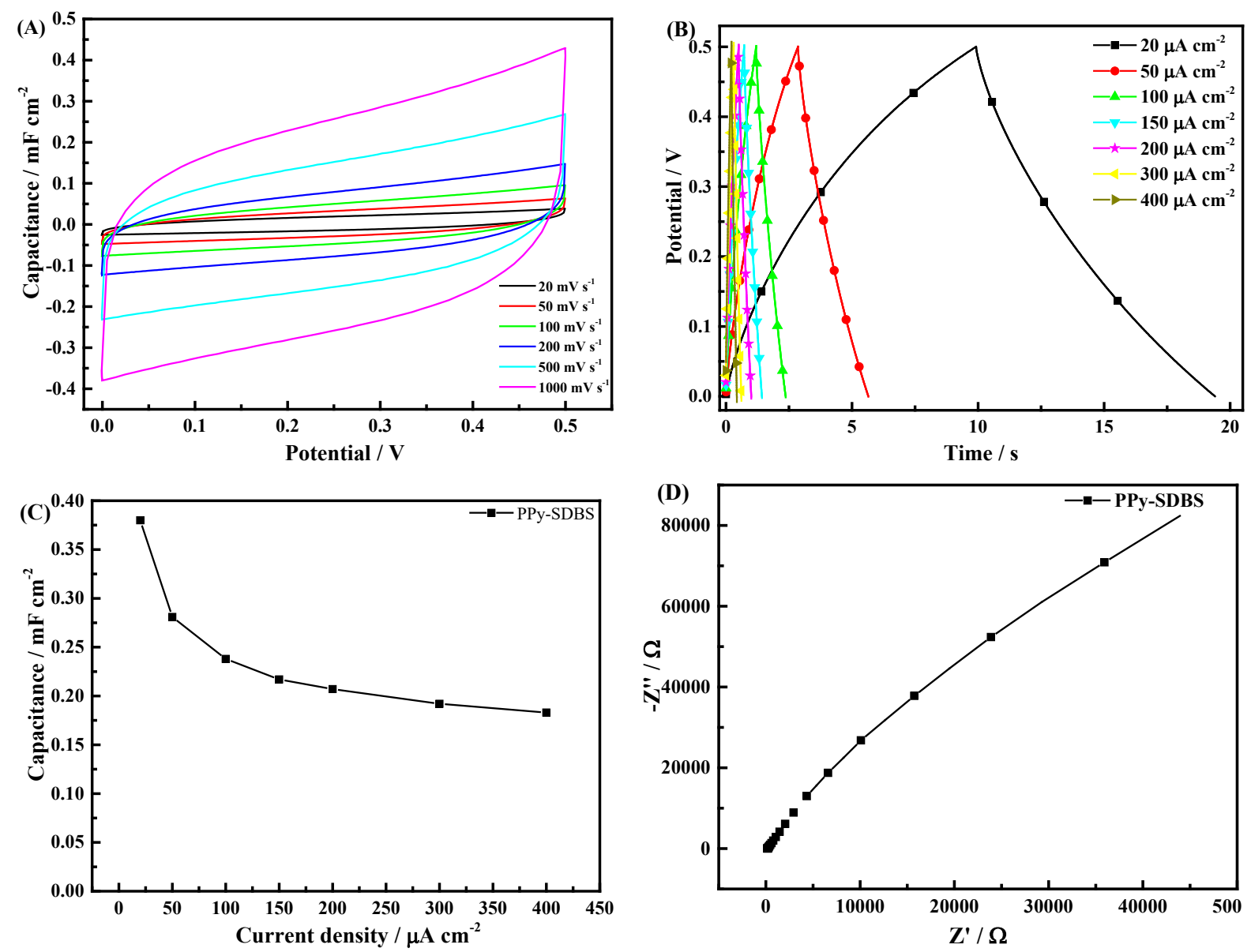

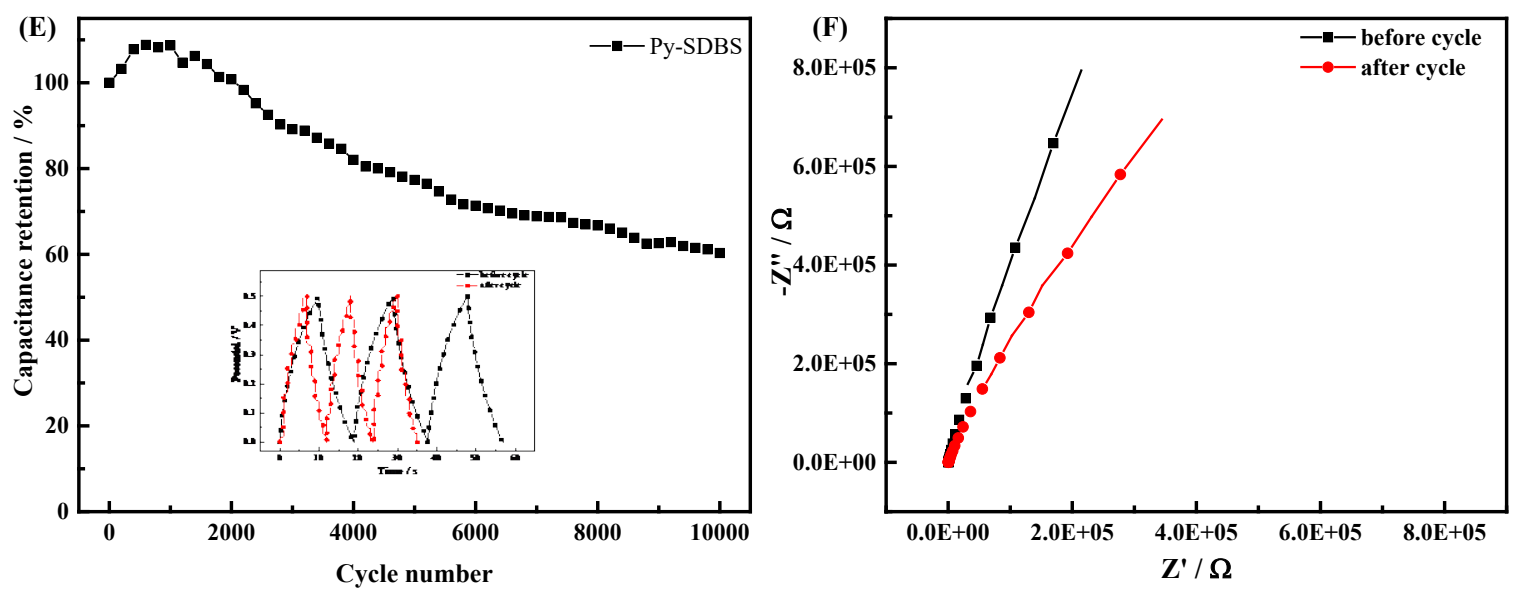

Figure S8. Electrochemical performance of P-SDBS symmetric Microsupercapacitors. (A) Areal capacitance of P-SDBS MSCs at different scan rate. (B) Galvanostatic charge/discharge curves of P-SDBS MSCs at different current densities. (C) Rate performances of P-SDBS MSCs at different current density. (D) Electrochemical impedance spectroscopy data of PSDBS MSCs tested at the open-circuit potential within the frequency range from $10^{-1}$ to $10^{5} \mathrm{~Hz}$. (E) Long-term charge-discharge cycling performance of the Py-SDBS MSCs device. Inset: The comparison of GCD curves before and after cycling test. (F) The comparison of EIS spectra before and after cycling test.
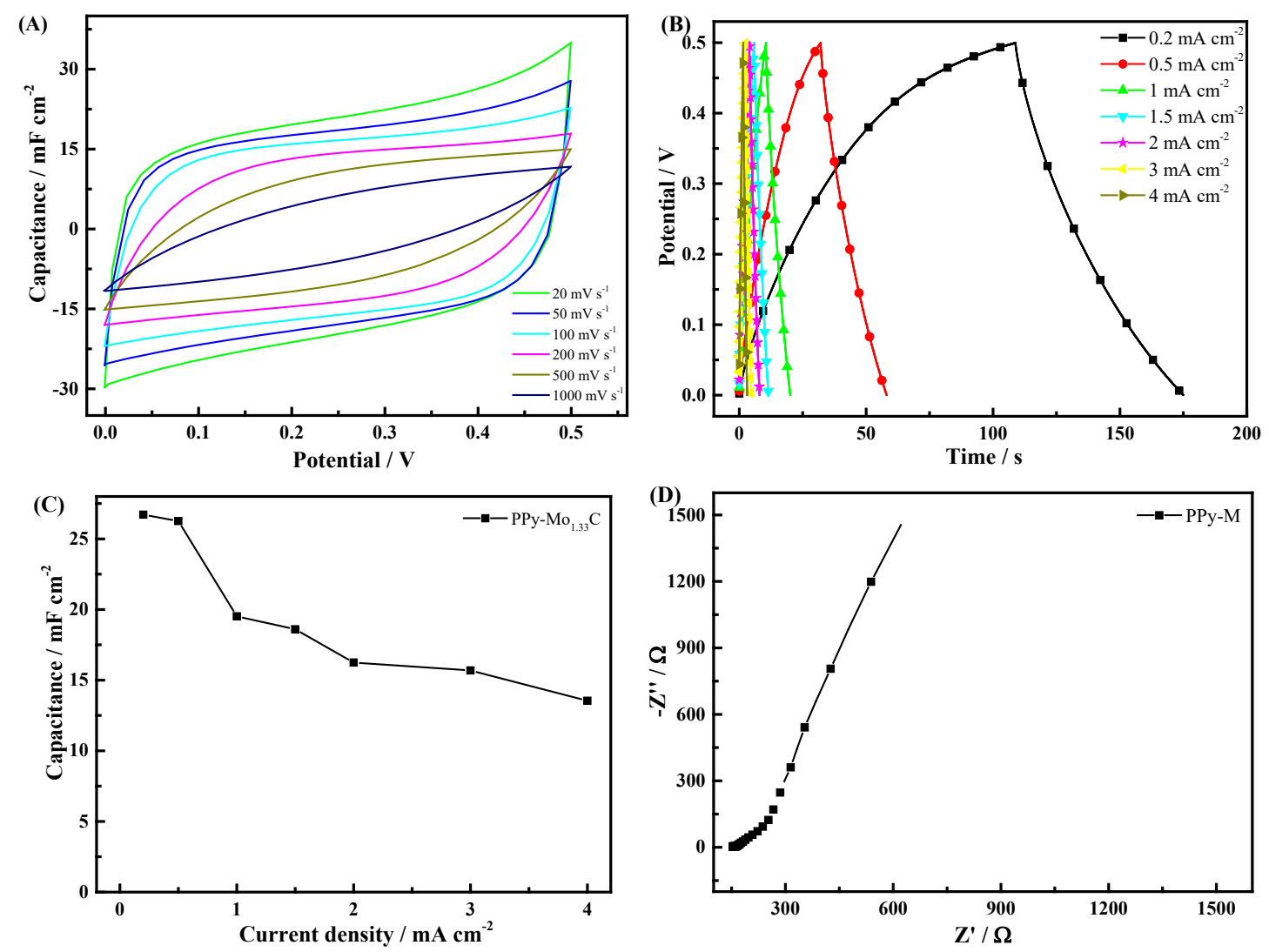

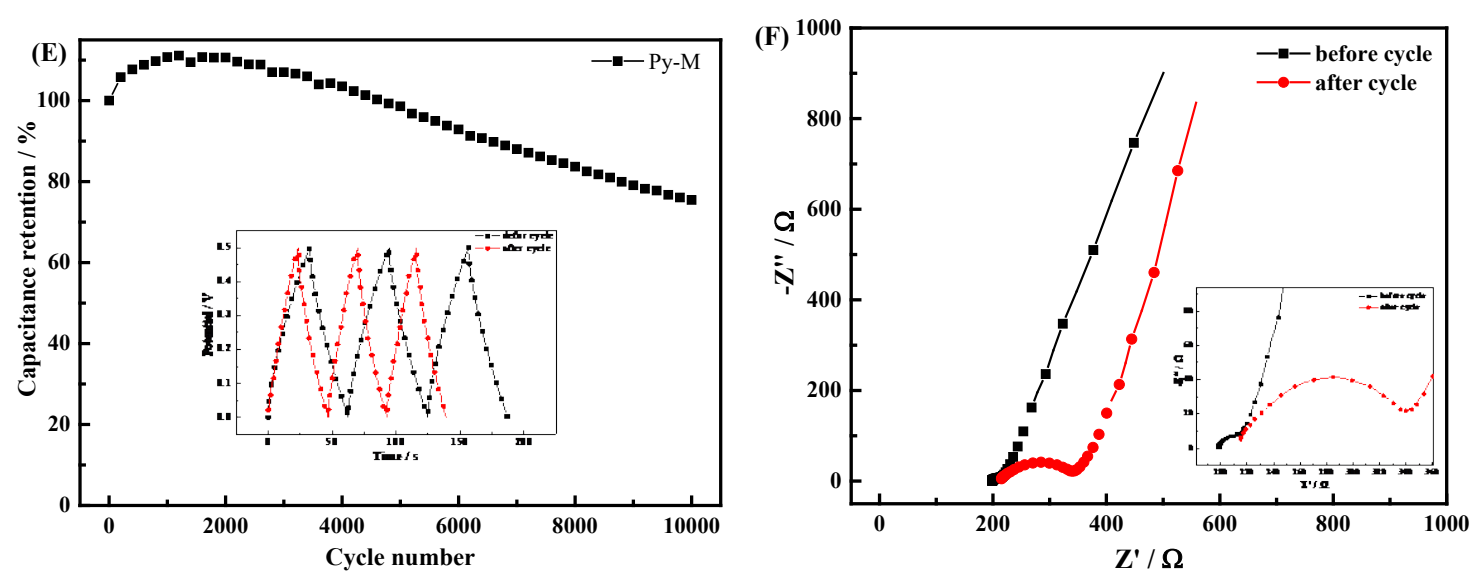

Figure S9. Electrochemical performance of P-M symmetric Microsupercapacitors. (A) Areal capacitance of P-M MSCs at different scan rate. (B) Galvanostatic charge/discharge curves of P-M MSCs at different current densities. (C) Rate performances of P-M MSCs at different current density. (D) Electrochemical impedance spectroscopy data of P-M MSCs tested at the open-circuit potential within the frequency range from $10^{-1}$ to $10^{5} \mathrm{~Hz}$. (E) Long-term chargedischarge cycling performance of the P-M MSCs device. Inset: The comparison of GCD curves before and after cycling test. (F) The comparison of EIS spectra before and after cycling test. Inset: the enlarged plot in the high frequency region.
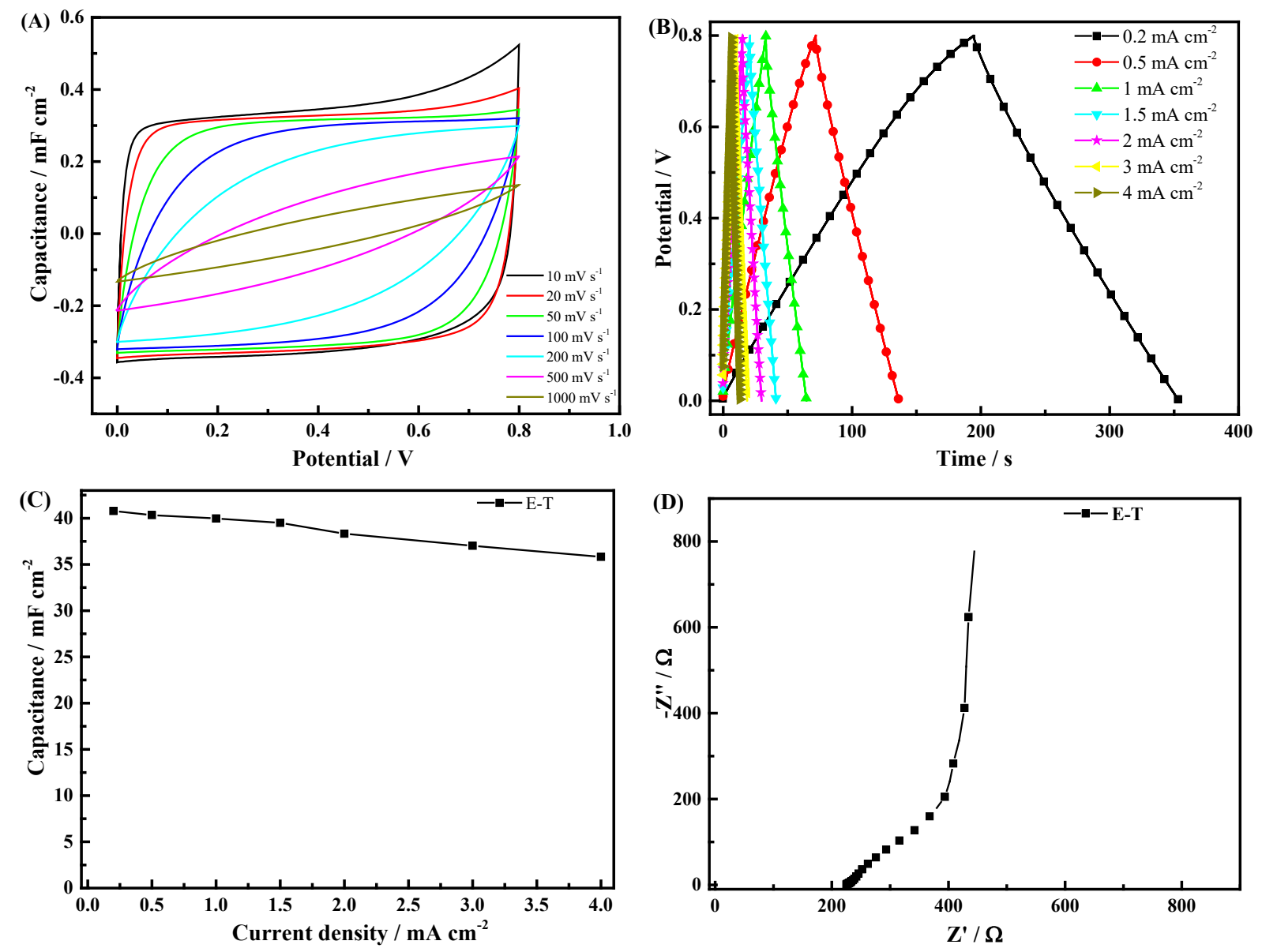

Figure S10. Electrochemical performance of E-T symmetric Microsupercapacitors. (A) Areal capacitance of E-T MSCs at different scan rate. (B) Galvanostatic charge/discharge curves of E-T MSCs at different current densities. (C) Rate performances of E-T MSCs at different 
current density. (D) Electrochemical impedance spectroscopy data of E-T MSCs tested at the open-circuit potential within the frequency range from $10^{-1}$ to $10^{5} \mathrm{~Hz}$.
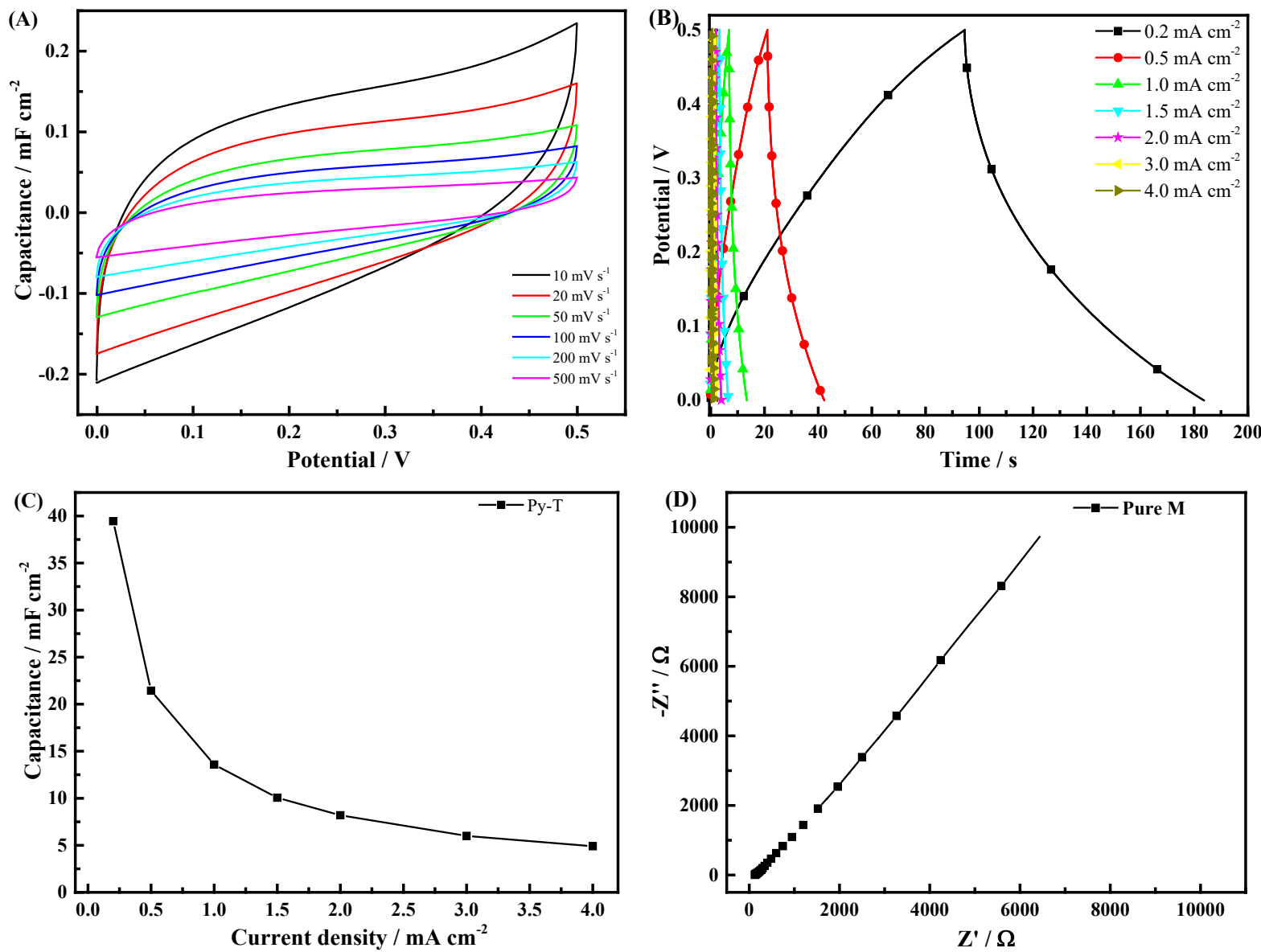

Figure S11. Electrochemical performance of P-T symmetric Microsupercapacitors. (A) Areal capacitance of P-T MSCs at different scan rate. (B) Galvanostatic charge/discharge curves of P-T MSCs at different current densities. (C) Rate performances of P-T MSCs at different current density. (D) Electrochemical impedance spectroscopy data of P-T MSCs tested at the opencircuit potential within the frequency range from $10^{-1}$ to $10^{5} \mathrm{~Hz}$.

\section{SEM of the E-N, P-S, E-T and P-T}
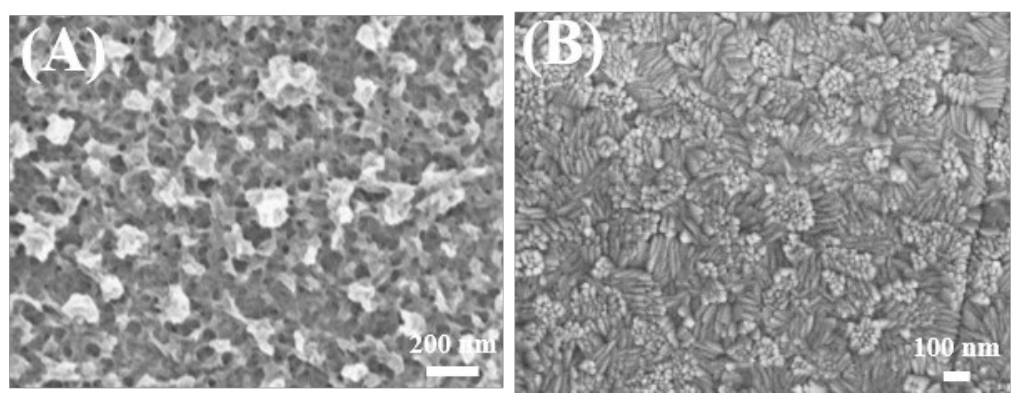
Figure S12. SEM image of (A) PEDOT prepared in $\mathrm{Na}_{2} \mathrm{SO}_{4}$ electrolyte (E-N), (B) PPy prepared in SDBS electrolyte (P-S).

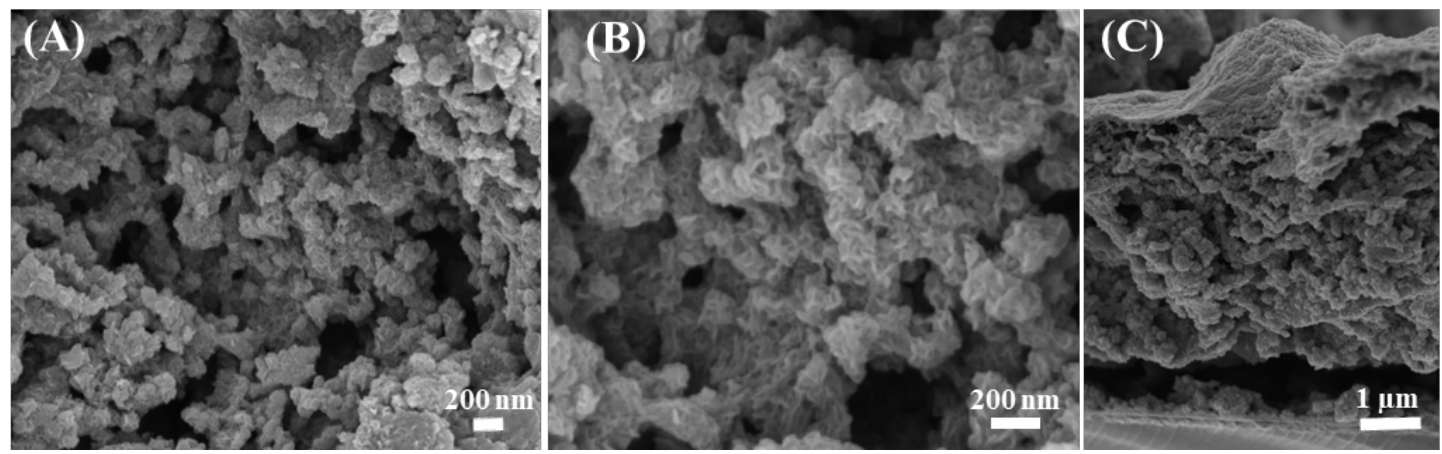

Figure S13. (A, B) SEM image of PEDOT prepared in $\mathrm{Ti}_{3} \mathrm{C}_{2}$ (E-T) film. (C) SEM image of the cross section of E-T film.
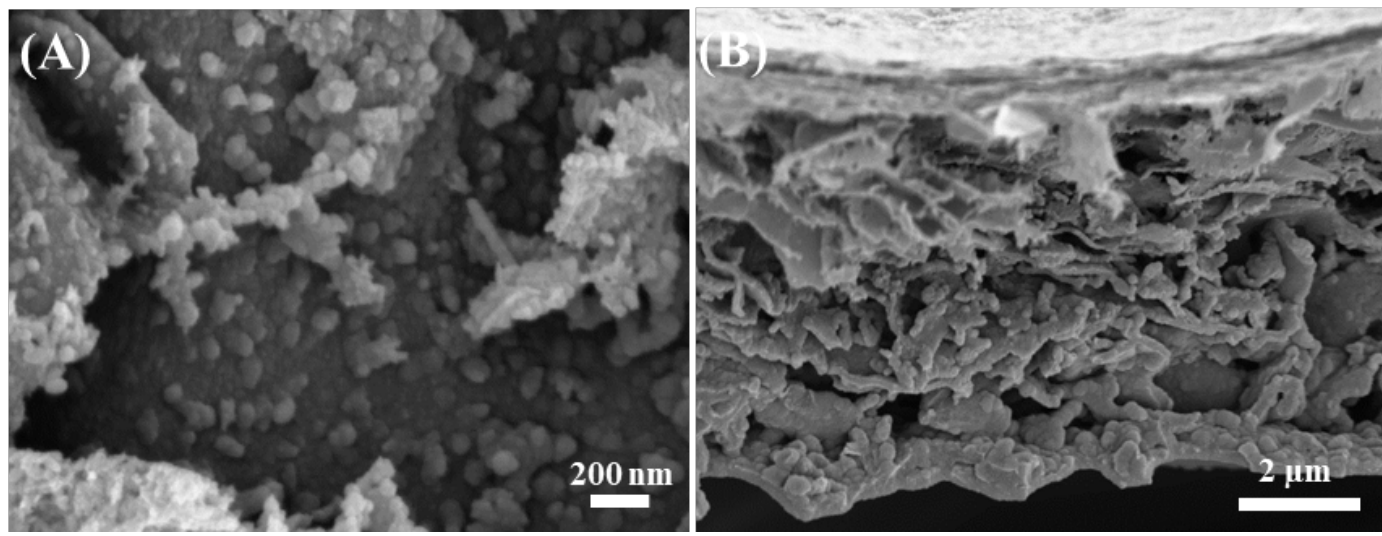

Figure S14. (A) SEM image of PPy prepared in $\mathrm{Ti}_{3} \mathrm{C}_{2}$ (P-T) film. (C) SEM image of the cross section of P-T film.

6. Nitrogen sorption isotherm measurements 

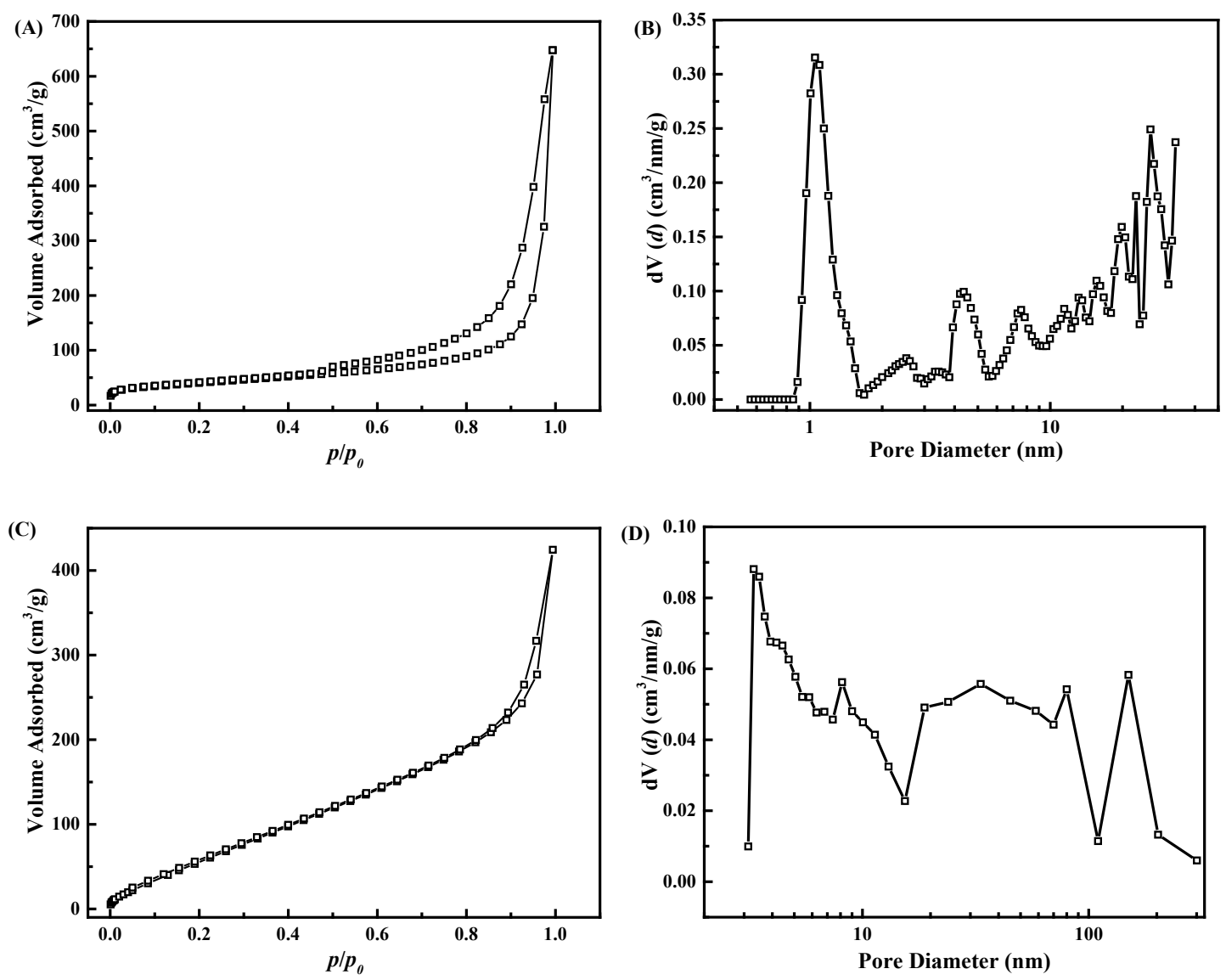

Figure S15. Nitrogen adsorption-desorption isotherm of the E-M film (A) and P-M film (C). DFT pore size distribution of the E-M film (B) and P-M film (D).

We conducted Nitrogen sorption isotherm measurements to investigate the porosity of the E-M and P-M films and observed that these films were highly porous. The BrunauerEmmett-Teller (BET) surface area of E-M film was evaluated to be as high as $930 \mathrm{~m}^{2}$ $\mathrm{g}^{-1}$. The pore-size distribution profile of E-M film revealed that the main pore size was $1.3 \mathrm{~nm}$ and the pore size of the distribution was about 5-40 nm (Figure S15B). The PM film exhibited a BET surface area of $860 \mathrm{~m}^{2} \mathrm{~g}^{-1}$. Using the nonlocal density function theory method, the pore size distribution of the P-M film was calculated to be about $3-$ $200 \mathrm{~nm}$ (Figure S15D) based on the adsorption and desorption data. These pores may form from the gap between the nanospheres of EP films, and corresponding to the free volume in polymer physics that makes small molecules such as gas, the anions diffuse freely in the region that is very deep from the polymer surface. However, for traditional conductive polymers, there are some $\pi-\pi$ aggregates in the polymer chains, preventing 
interaction between electrolyte anions with polymer segments inside the aggregate, which yields low electrochemical performance. The introduction of MXene to the skeletal structure of conductive polymers will increase molecular spacing and facilitate the movement of the dopant ions into every electroactive site. Finally, the electrochemical properties of the composite film could be enhanced. This indicated that the microporous structure with the increased distance between the molecules would be advantageous for electrolyte ion migration, facilitating the doping and dedoping process, resulting in improved capacitance performance.

\section{AFM and TEM of single layer}

From the section TEM image of multilayer $\mathrm{Mo}_{1.33} \mathrm{C}$ (Figure $\mathrm{S} 16 \mathrm{~A}$ ), we can deduce that the lattice spacing of each layer is approximately about $1.1 \mathrm{~nm}$, consistent with the thickness of the single layer MXene obtained in the AFM measurements (Figure S16B).
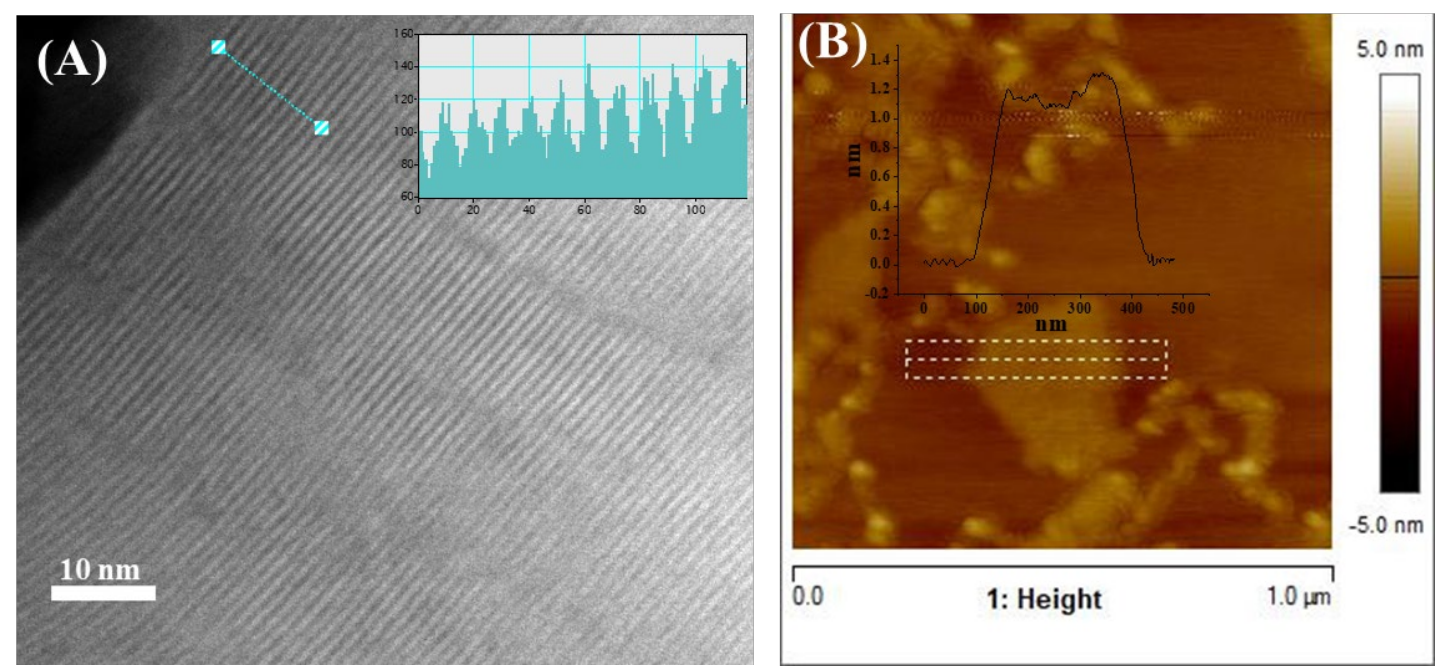

Figure S16. (A) The side view TEM image of multilayer Mo1.33 C MXene flake, (B) AFM of single layer Mo1.33 C MXene.

\section{High-resolution core-level XPS}



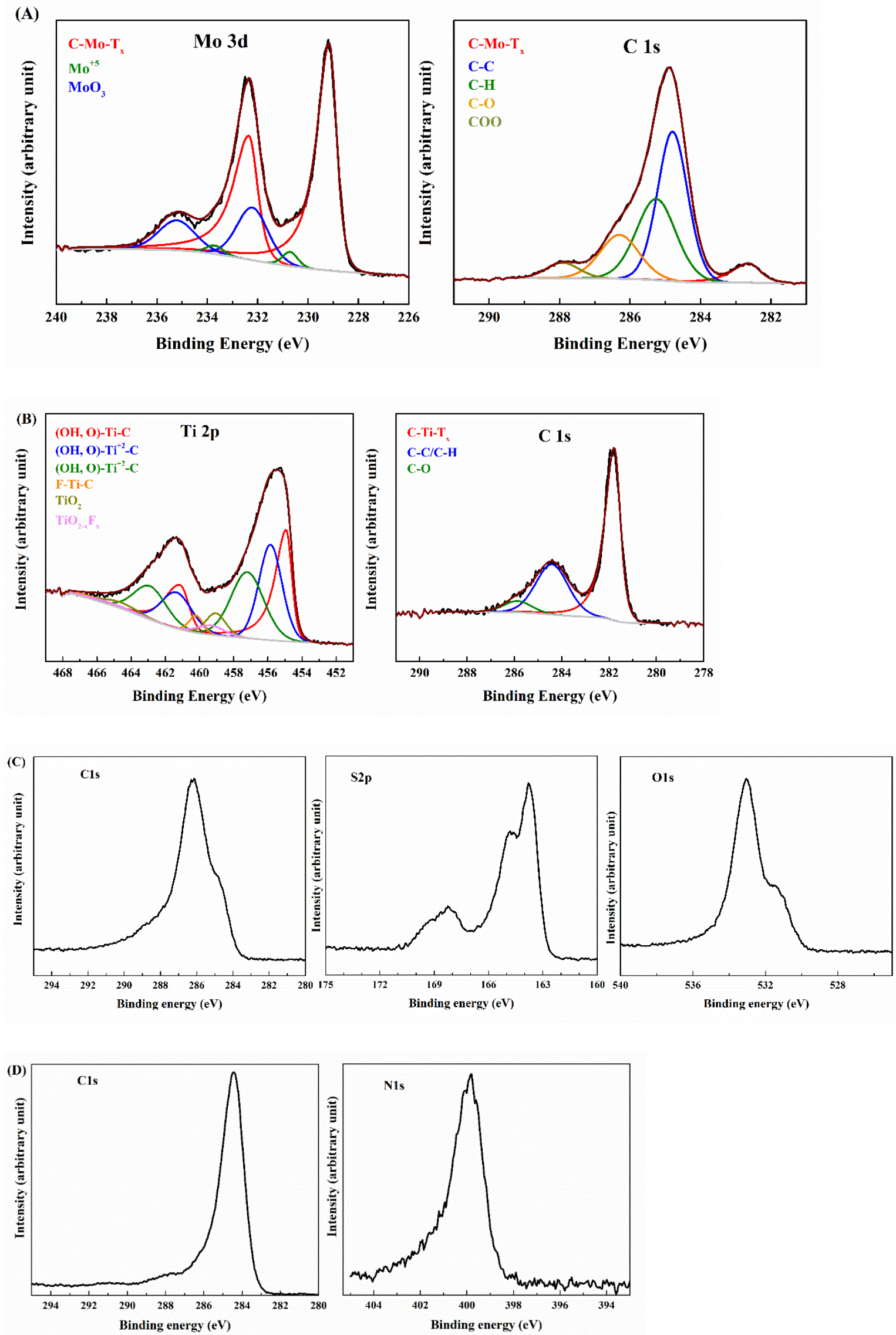

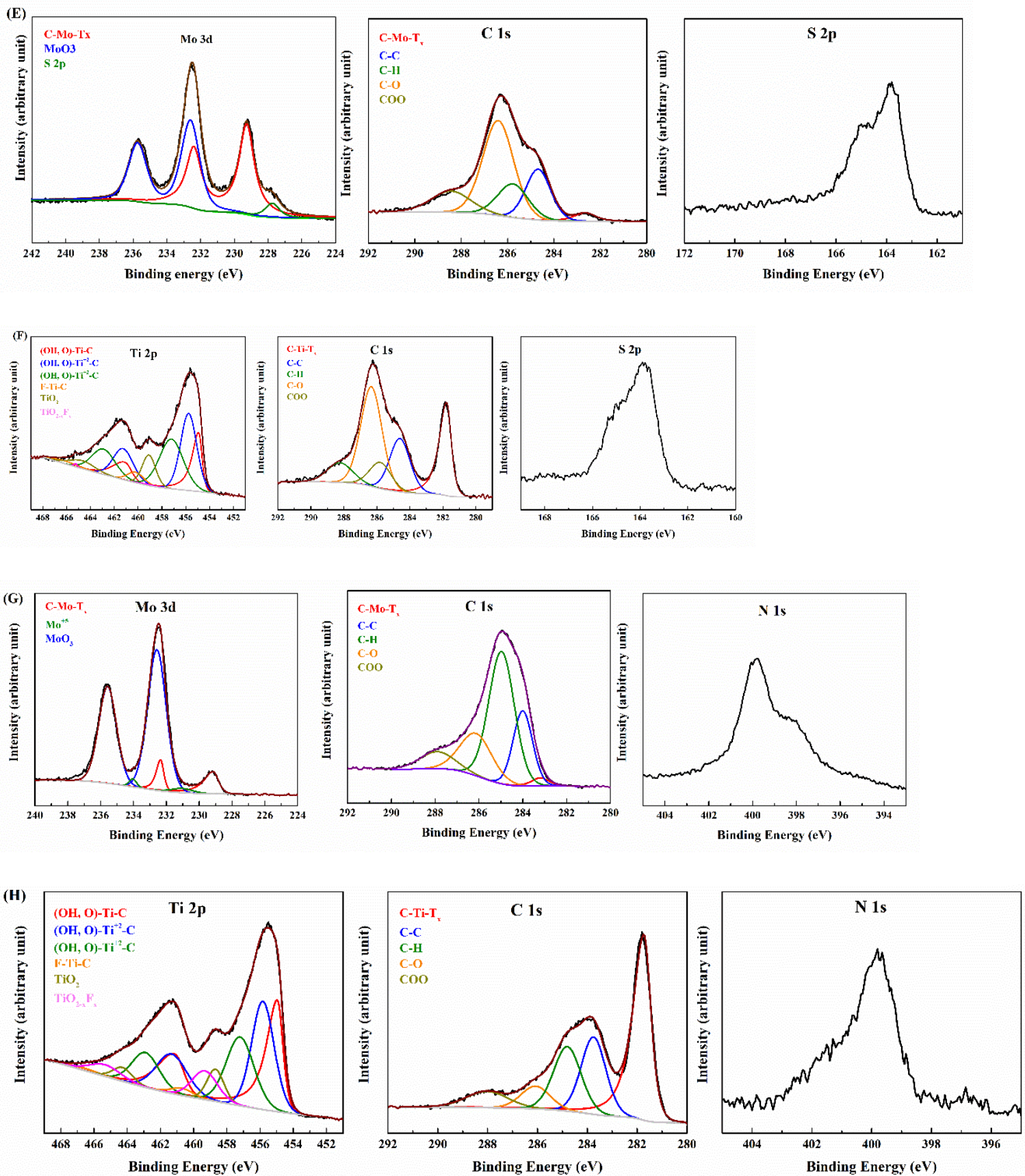

Figure S17. High-resolution XPS spectra of (A) $\mathrm{Mo}_{1.33} \mathrm{C}$, (B) $\mathrm{Ti}_{3} \mathrm{C}_{2}$, (C) E-Na, (D) P-SDBS, (E) E-M, (F) E-T, (G) Py-M, (H) Py-T.

From the Mo 3d, Ti 2p regions, peaks for MXene are identified, labeled in the figures as C-Mo$\mathrm{T}_{\mathrm{x}}$ in $\mathrm{Mo} 3 \mathrm{~d}\left(\mathrm{Mo}_{1.33} \mathrm{CT}_{\mathrm{x}}\right)$ and $(\mathrm{OH}, \mathrm{O})-\mathrm{Ti}-\mathrm{C},(\mathrm{OH}, \mathrm{O})-\mathrm{Ti}^{+2}-\mathrm{C},(\mathrm{OH}, \mathrm{O})-\mathrm{Ti}^{+3}-\mathrm{C}$ and $\mathrm{F}-\mathrm{Ti}-\mathrm{C}$ for Ti $2 p$ region $\left(\mathrm{Ti}_{3} \mathrm{C}_{2} \mathrm{~T}_{\mathrm{x}}\right)$ after polymerization the peaks identified for MXene are reduced and the peaks identified for oxides are increased this is more apparent in the $\mathrm{Mo}_{1.33} \mathrm{CT}_{\mathrm{x}}$ case $^{3,4}$. 
The spectra measured for the MXenes with polymers show features from the MXene (Mo 3d and $\mathrm{Ti} 2 \mathrm{p}$ ) as well as the $\mathrm{C} 1 \mathrm{~s}$ regions also the polymer is shown from the $\mathrm{S} 2 \mathrm{p}$ region in the PEDOT and $\mathrm{N}$ 1s region in the polypyrrole. It is confirm the incorporation of MXenes into the polymer films during the electrochemical polymerization process.

\section{EDS of the sample}
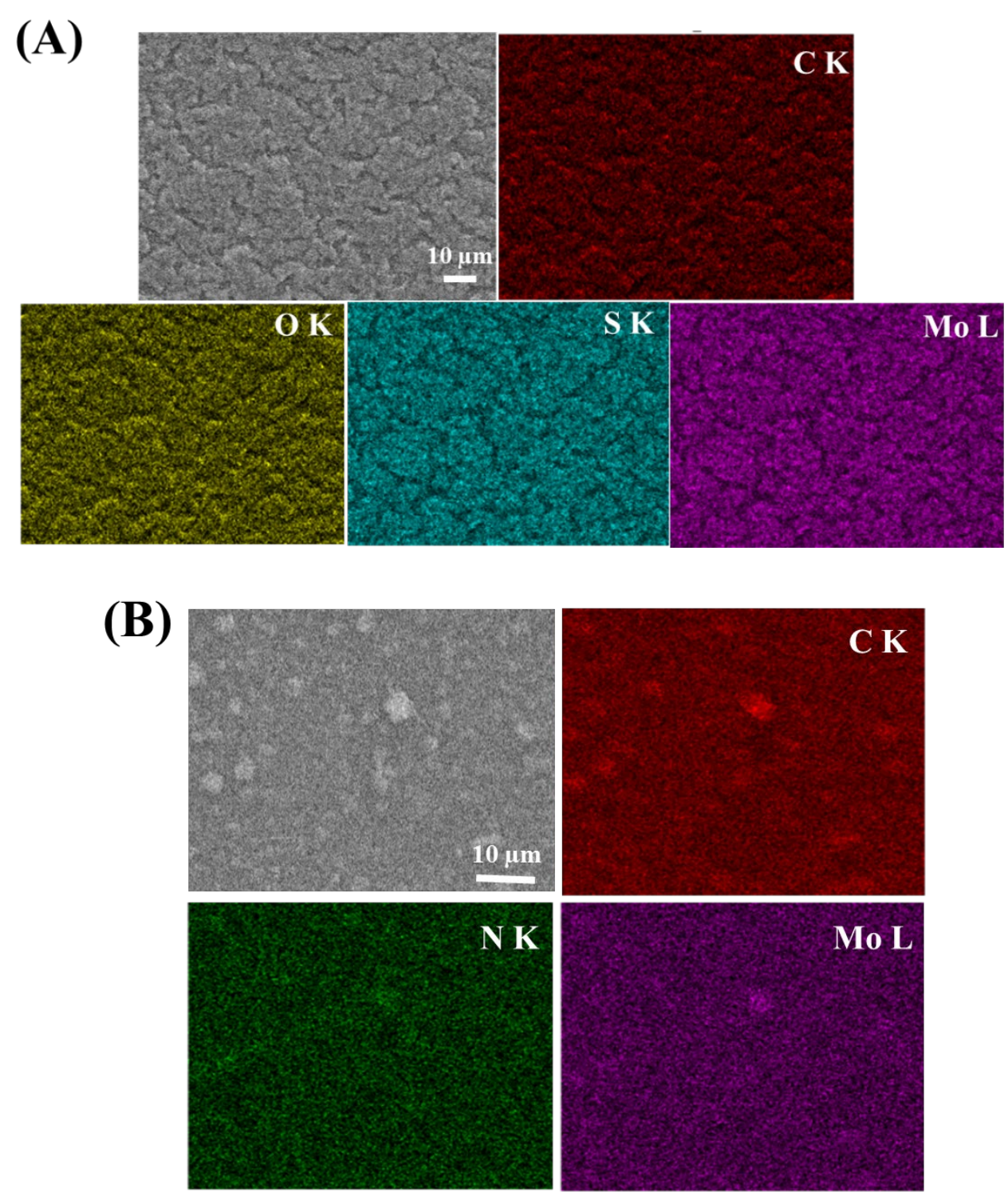

Figure S18. The surface EDS elemental mapping images of (A) E-M (C, O, S, Mo) and (B) P$\mathrm{M}(\mathrm{C}, \mathrm{N}, \mathrm{Mo})$. 
10. UV and FT-IR of sample

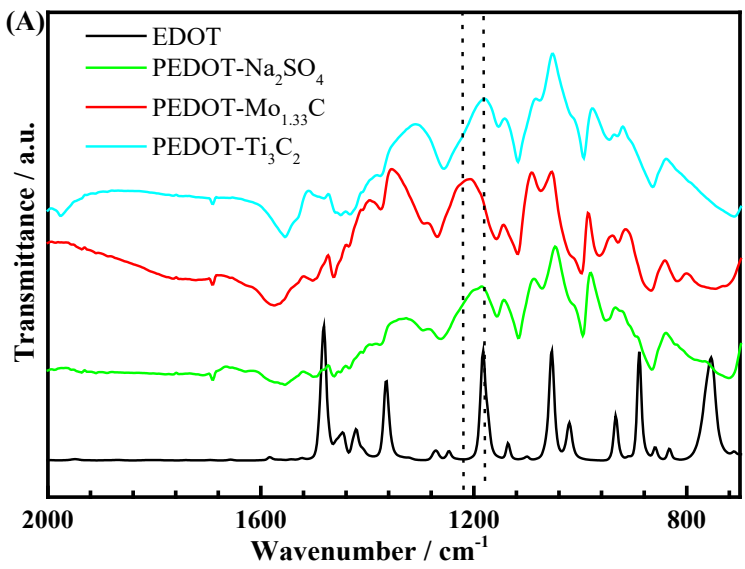

Figure S19. The FT-IR spectra of (A) EDOT and corresponding polymer, (B) pyrrole and corresponding polymer.
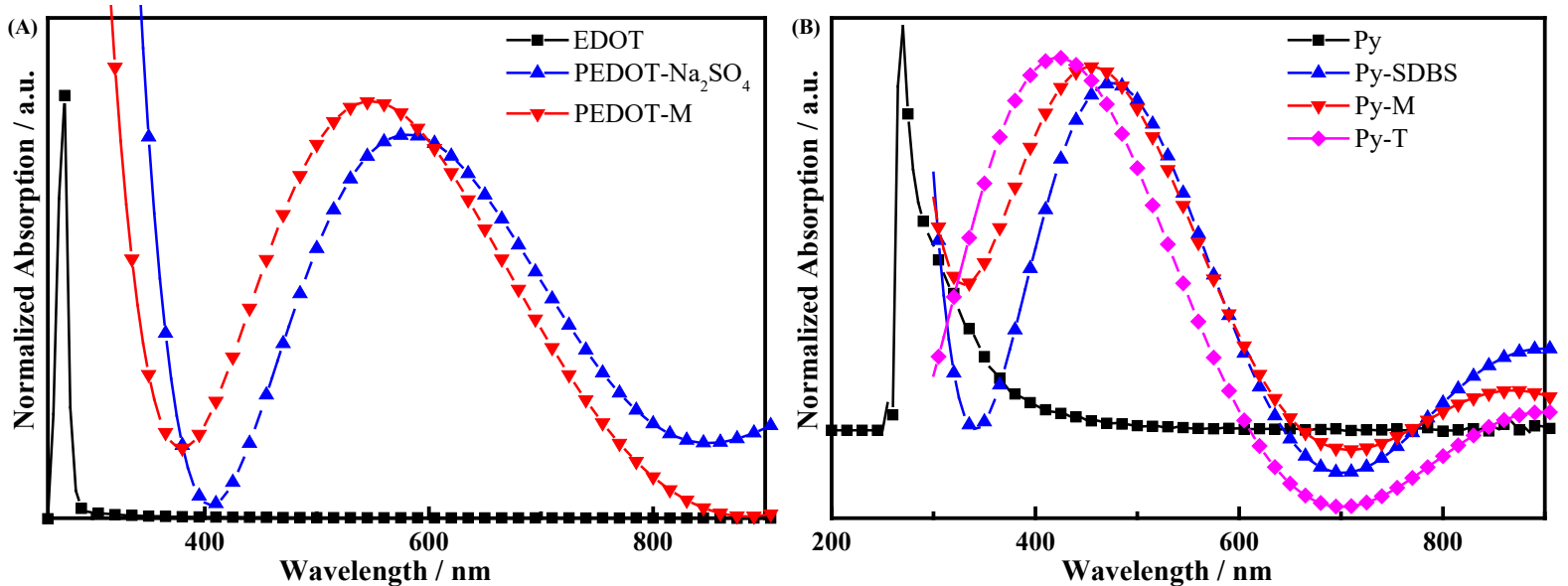

Figure S20. Absorption spectra of (A) EDOT and corresponding polymer, (B) pyrrole and corresponding polymer. 


\section{The content of composite film component}

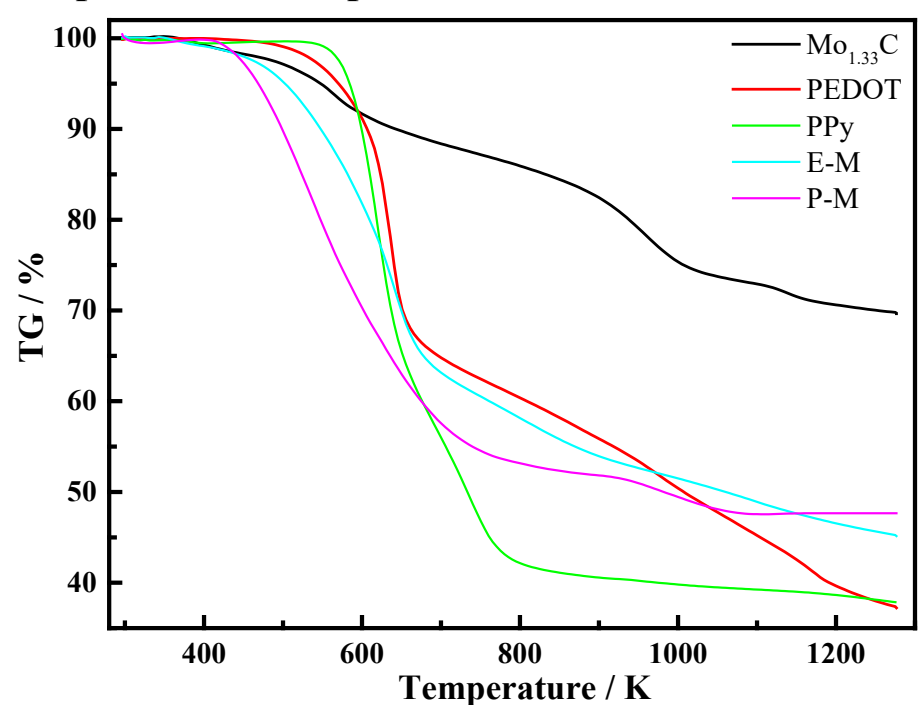

Figure S21. Thermogravimetric analysis curves of $\mathrm{Mo}_{1.33} \mathrm{C}$, PEDOT, PPy, E-M and P-M films under an Argon atmosphere.
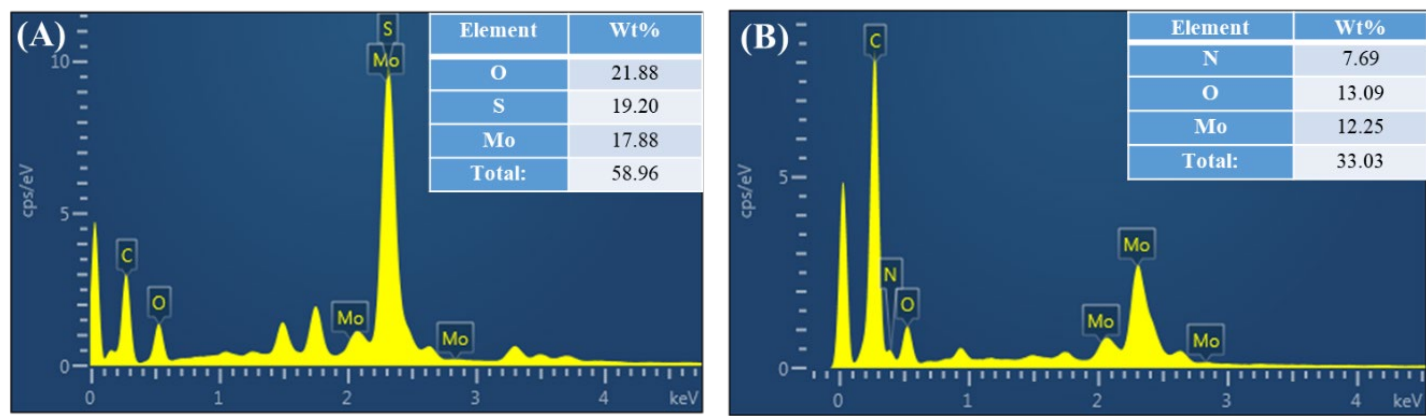

Figure S22. EDX spectrum of E-M (A) and P-M (B).

In order to investigate the content of MXene and polymer in the polymer/MXene composite, we conducted thermogravimetric analysis (TG) and EDX experiments. For the composite films, the MXene is only doped into polymer during the electrochemical polymerization of monomer, and there is no chemical reaction with polymer. Therefore, we assume that in the composite film, the thermal weight loss process of MXene and polymer does not affect each other. From the TG curve, we can calculate that the content of MXene in the E-M and P-M composite film is $24.6 \%$ and $30.6 \%$, respectively. In addition, from the results of EDX of E-M and P-M, the content of MXene in the E-M and P-M composite film is $23.5 \%$ and $32 \%$, in consistent with the results of TG. 


\section{Electrochemical Performance of $\mathbf{M n O}_{2}$-based Microsupercapacitors}
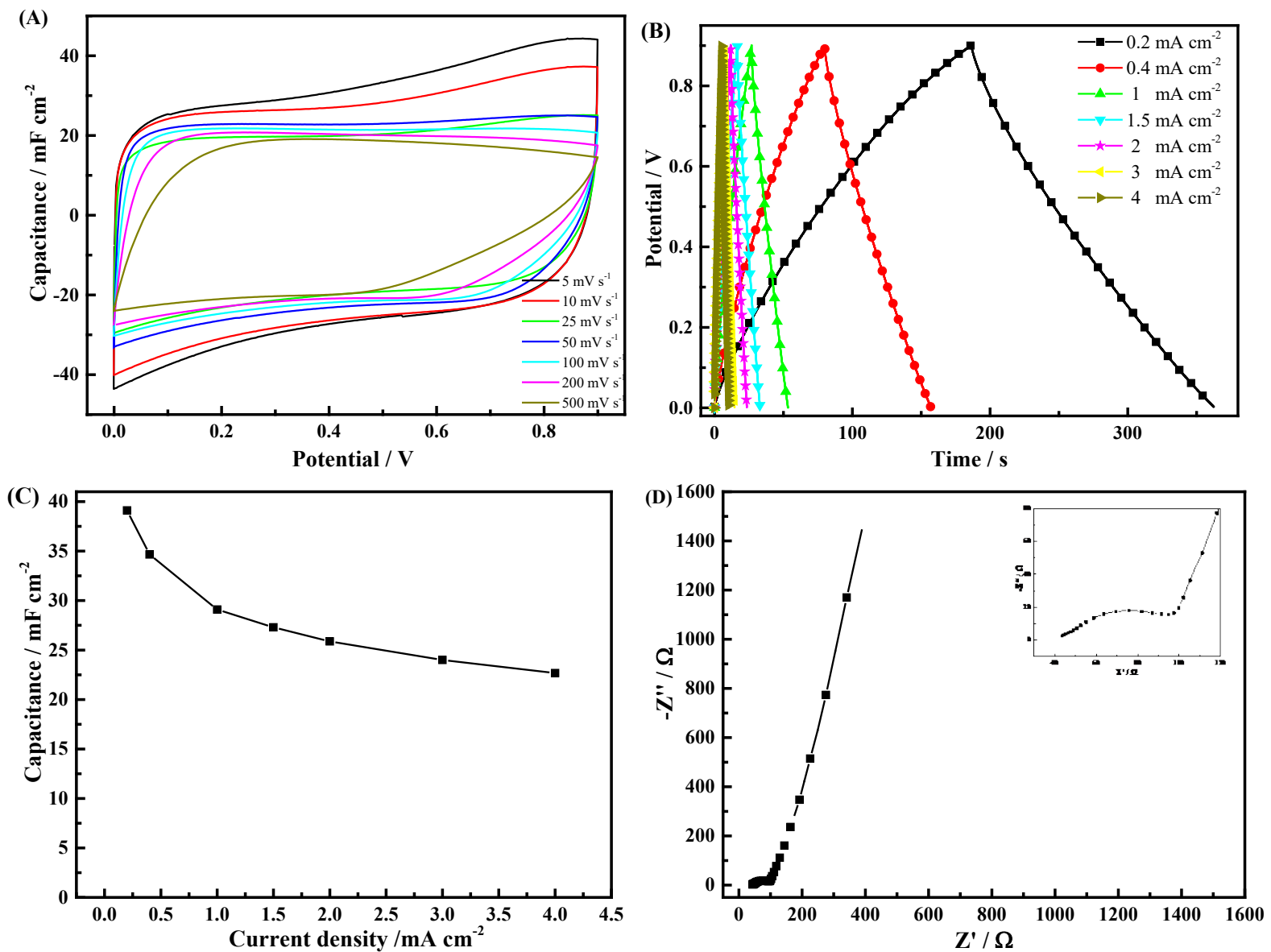

Figure S23. Electrochemical performance of $\mathrm{MnO}_{2}$ symmetric Microsupercapacitors A) detailed CV curves of the $\mathrm{MnO}_{2}$ MSCs tested under different scan rates, B) the galvanostatic charging/discharging curves of the $\mathrm{MnO}_{2}$ MSCs with different current densities, C) The areal capacitances of $\mathrm{MnO}_{2} \mathrm{MSCs}$ at different current density, D) Nyquist plot of the device tested at the opencircuit potential within the frequency range from $10^{-1}$ to $10^{5} \mathrm{~Hz}$. The above inset shows the enlarged plot in the high-frequency region.

The electrochemical performance of the $\mathrm{MnO}_{2} \mathrm{MSC}$ s were investigated in a two-electrode configuration. Typical CV curves of the $\mathrm{MnO}_{2} \mathrm{MSCs}$ at different scan rates are shown in Figure S23A, exhibiting a good rectangular shape up to $500 \mathrm{mV} \mathrm{s}^{-1}$, which indicates a low resistance and good reversibility. Isosceles triangle shaped charge-discharge curves indicate good reversibility of the $\mathrm{MnO}_{2}$ MSCs at different current densities, as shown in Figure S23B, which is in good agreement with the CV curves. The areal capacitances at different current density for $\mathrm{MnO}_{2} \mathrm{MSC}$ are shown in Figure S23C. The $\mathrm{MnO}_{2} \mathrm{MSC}$ s exhibits an areal capacitance of 39.1 $\mathrm{mF} \mathrm{cm}$ at $0.2 \mathrm{~mA} \mathrm{~cm}$, maintaining $22.7 \mathrm{mF} \mathrm{cm}^{-2}$ at $4 \mathrm{~mA} \mathrm{~cm}^{-2}$. The electrochemical 
capacitive behavior of the $\mathrm{MnO}_{2}$ MSCs was further investigated by electrochemical impedance spectroscopy (EIS), as shown in Figure S23D. It can be seen that the complex plane plots of $\mathrm{MnO}_{2} \mathrm{MSC}$ show a larger slope at low frequency, which indicates fast ion diffusion. At high frequency, see inset in Figure S23D, MSCs shows a smaller charge-transport semicircle which indicates a rapid electron transfer inside the $\mathrm{MnO}_{2}$ film.

\section{3. $\mathrm{SEM}$ of EP $\mathrm{MnO}_{2}$}

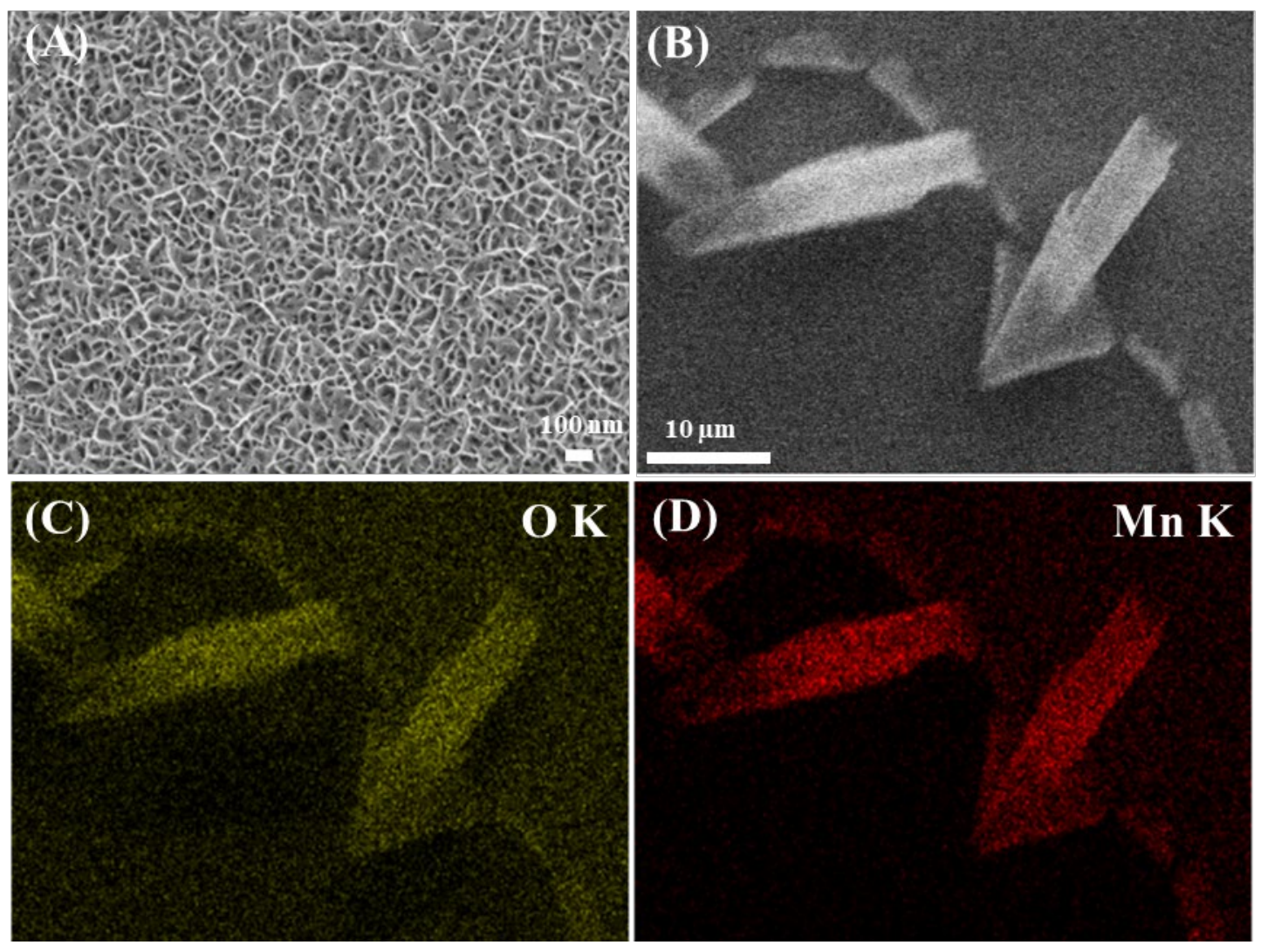

Figure S24. (A) High-magnification SEM image of the $\mathrm{MnO}_{2}$. SEM image (B) and corresponding elemental mapping images of $\mathrm{O}(\mathrm{C})$, and $\mathrm{Mn}(\mathrm{D})$. 


\section{Electrochemical performance and stability of AMSCs}

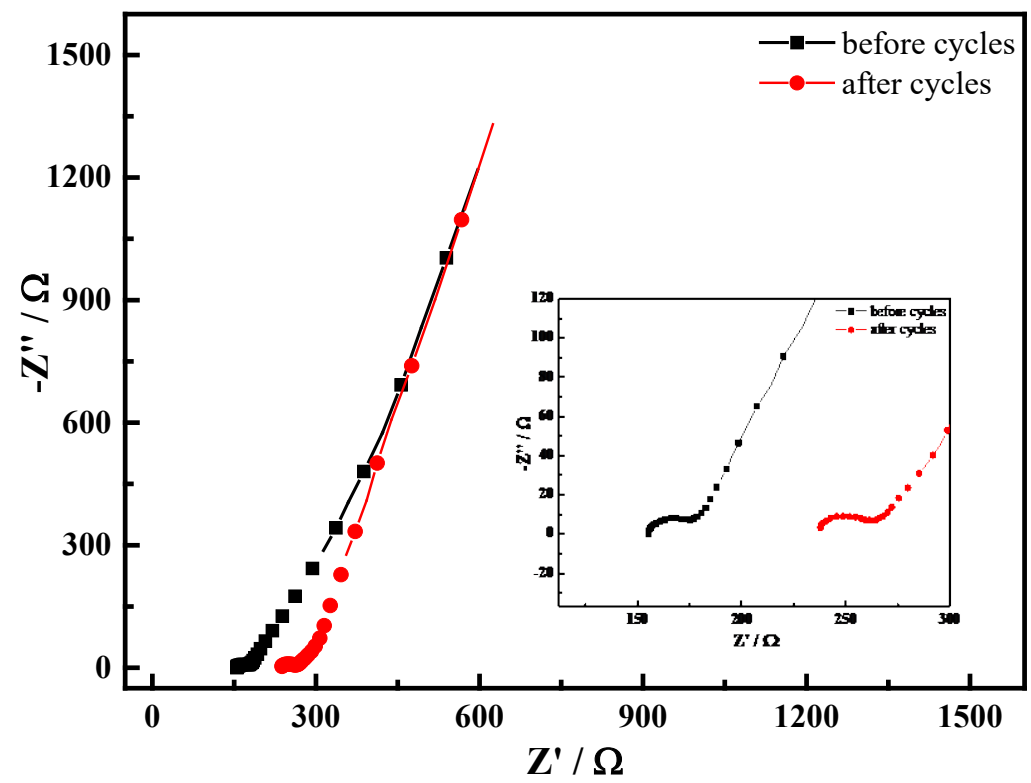

Figure S25. Changes of the Nyquist plots of AMSCs device before and after 10000 cycles at a current of $1.5 \mathrm{~mA} \mathrm{~cm}^{-2}$.

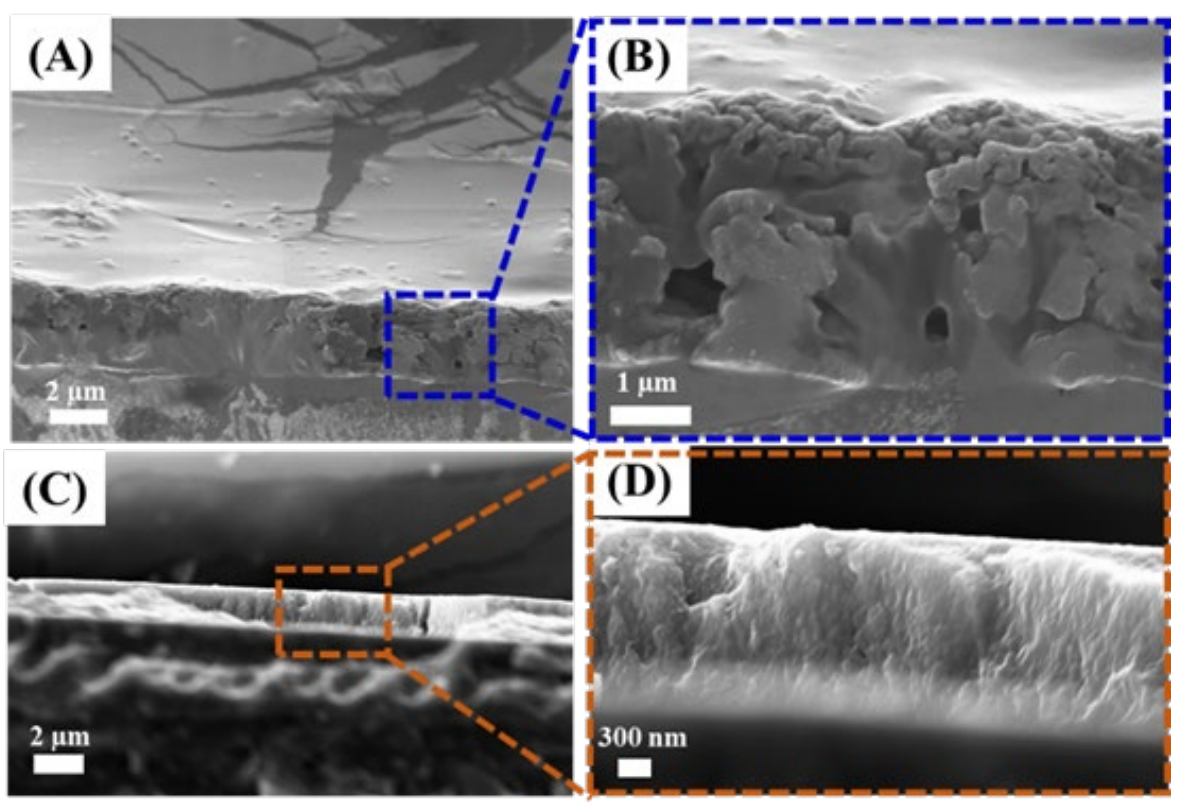

Figure S26. Cross-sectional SEM image of the device after cycling test. (A) E-M, (C) $\mathrm{MnO}_{2}$. The left side SEM image $(B, D)$ is an enlarged view of the active materials part of the device.

After cycling, the AMSCs devices were studied by SEM and the cross-sectional SEM images of the device ((A) E-M, (C) $\left.\mathrm{MnO}_{2}\right)$ were shown in Figure S26. After 10000 cycles, the morphology of the E-M almost maintain the nanosphere structures as before the cycling (part of the electrolyte penetrates into the E-M film), indicating that the EP composite film were 
effectively stabilized by the infiltration of MXene. In addition, $\mathrm{MnO}_{2}$ also maintained the microstructure after stability testing.

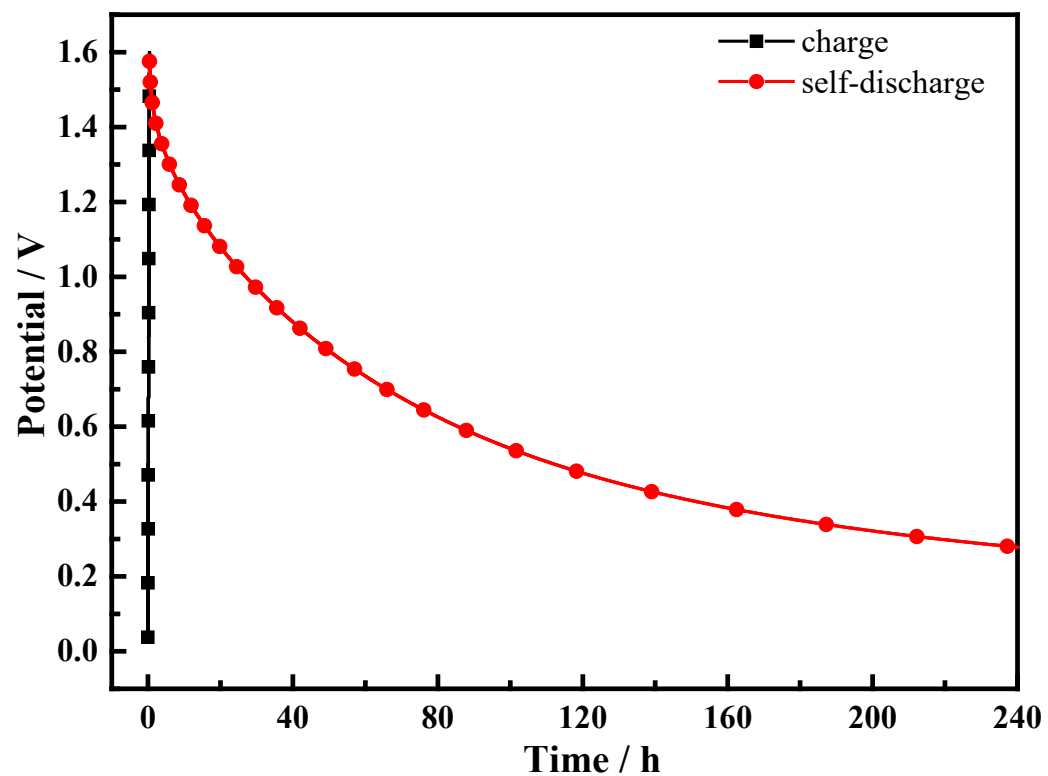

Figure S27. Self-discharge behaviour of AMSCs device

Table S2. The capacitance performance of MSCs at different current density.

\begin{tabular}{|c|c|c|c|c|c|c|}
\hline \multirow{2}{*}{$\begin{array}{c}\text { Current } \\
\text { density } \\
\left(\mathrm{mA} \mathrm{cm}^{-2}\right)\end{array}$} & \multicolumn{2}{|c|}{ E-M } & \multicolumn{2}{|c|}{ P-M } & \multicolumn{2}{|c|}{ AMSCs } \\
\hline & $\begin{array}{c}\mathrm{C}_{\mathrm{A}} \\
\left(\mathrm{mF} \mathrm{cm}^{-2}\right)\end{array}$ & $\begin{array}{c}\mathrm{C}_{\mathrm{V}} \\
\left(\mathrm{F} \mathrm{cm}^{-3}\right)\end{array}$ & $\begin{array}{c}\mathrm{C}_{\mathrm{A}} \\
\left(\mathrm{mF} \mathrm{cm}^{-2}\right)\end{array}$ & $\begin{array}{c}\mathrm{C}_{\mathrm{V}} \\
\left(\mathrm{F} \mathrm{cm}^{-3}\right)\end{array}$ & $\begin{array}{c}\mathrm{C}_{\mathrm{A}} \\
\left(\mathrm{mF} \mathrm{cm}^{-2}\right)\end{array}$ & $\begin{array}{c}\mathrm{C}_{\mathrm{V}} \\
\left(\mathrm{F} \mathrm{cm}^{-3}\right)\end{array}$ \\
\hline 0.2 & 47.4 & 225.6 & 26.7 & 333.9 & 71.2 & 652.5 \\
\hline 0.5 & 47.3 & 224.9 & 26.3 & 328.4 & 69.5 & 636.9 \\
\hline 1.0 & 47.4 & 223.9 & 19.5 & 243.9 & 60 & 549.9 \\
\hline 1.5 & 46.6 & 221.6 & 18.6 & 232.5 & 56.4 & 516.9 \\
\hline 2.0 & 45.7 & 217.7 & 16.3 & 203.1 & 49.4 & 452.7 \\
\hline 3.0 & 44.8 & 213.0 & 15.7 & 196.1 & 42.5 & 389.5 \\
\hline 4.0 & 44.0 & 209.7 & 13.5 & 169.3 & 42.4 & 388.6 \\
\hline
\end{tabular}

Table S3. Electrochemical performance of microsupercapacitors featuring a variety of electrodes materials such as $\mathrm{MXene}$, Graphene, polymers, $\mathrm{MnO}_{2}$ and their hybrid materials.

\begin{tabular}{ccccccc}
\hline Electrode Materials & Potential/V & electrolyte & $\mathrm{C}_{\mathrm{A}} / \mathrm{mF} \mathrm{cm}^{-2}$ & $\begin{array}{c}\mathrm{E} / \mathrm{mW} \\
\mathrm{h} \mathrm{cm}-3\end{array}$ & $\begin{array}{c}\mathrm{P} / \mathrm{W} \\
\mathrm{cm}^{-3}\end{array}$ & Ref. \\
\hline $\mathrm{Ti}_{3} \mathrm{C}_{2} \mathrm{~T}_{\mathrm{x}}$ & $0-0.6$ & ${\mathrm{PVA} / \mathrm{H}_{2} \mathrm{SO}_{4}}$ & 27 & 18 & 0.7 & 5 \\
PANI & $0-0.8$ & ${\mathrm{PVA} / \mathrm{H}_{2} \mathrm{SO}_{4}}$ & 20.4 & 7.4 & 8 & 6 \\
$\mathrm{LSG} / \mathrm{MnO}_{2}$ & $0-0.9$ & $1.0 \mathrm{M} \mathrm{Na}_{2} \mathrm{SO}_{4}$ & 384 & 8000 & 10.3 & 7 \\
$\mathrm{LSG}$ & $0-0.8$ & $\mathrm{PVA} / \mathrm{H}_{3} \mathrm{PO}_{4}$ & 8.19 & 5.1 & 2.4 & 8
\end{tabular}




\begin{tabular}{|c|c|c|c|c|c|c|}
\hline SWCNT & $0-0.8$ & $\mathrm{PVA}-\mathrm{H}_{3} \mathrm{PO}_{4}$ & 0.521 & 0.18 & 11 & 9 \\
\hline PPy & $0-0.5$ & $\mathrm{PVA} / \mathrm{H}_{2} \mathrm{SO}_{4}$ & 8.15 & 15.25 & 0.89 & 10 \\
\hline N-doped MGFs & $0-3.0$ & $\begin{array}{c}\text { EMIBF }_{4} / \\
\text { PVDF-HFP }\end{array}$ & 306.3 & 0.957 & 15 & 11 \\
\hline $\mathrm{Ni} @ \mathrm{MnO}_{2}$ & $0-0.8$ & $\begin{array}{c}\mathrm{PVA} / \mathrm{CH}_{3} \mathrm{CO} \\
\mathrm{OLi}\end{array}$ & 52.6 & 11.1 & 39.6 & 12 \\
\hline $\mathrm{rGO} / / \mathrm{Ti}_{3} \mathrm{C}_{2} \mathrm{~T}_{\mathrm{x}}$ & $0-1.0$ & $\mathrm{PVA} / \mathrm{H}_{2} \mathrm{SO}_{4}$ & 2.4 & 8.6 & 0.2 & 13 \\
\hline $\mathrm{Ti}_{3} \mathrm{C}_{2} \mathrm{~T}_{\mathrm{x}}$ & $0-0.6$ & $\mathrm{PVA} / \mathrm{H}_{2} \mathrm{SO}_{4}$ & 61 & 10.8 & 4.7 & 14 \\
\hline $\begin{array}{c}\text { Graphene/ } \\
\mathrm{MnO}_{2} / \text { Silver } \\
\text { Nanowire }\end{array}$ & $0-0.9$ & $0.5 \mathrm{M} \mathrm{Na}_{2} \mathrm{SO}_{4}$ & 35.2 & 2.3 & $\begin{array}{c}0.16 \\
2\end{array}$ & 15 \\
\hline E-M//MnO & $0-1.6$ & PVA/LiCl & 69.45 & 250.1 & 32.9 & $\begin{array}{l}\text { This } \\
\text { work }\end{array}$ \\
\hline
\end{tabular}

$\mathrm{C}_{\mathrm{A}}$ : areal capacitance; E: energy density; P: power density; PANI: polyaniline; PPy: polypyrrole; $\mathrm{EMIBF}_{4}$ : 1-eutyl-3-methylimidazolium tetrafluoroborate; PVDF-HFP: poly(vinylidene fluoride-cohexafluoropropylene); LSG: laser-scribed graphene; SWCNT: single-walled carbon nanotubes; MGFs: microfluidic-directed graphene fibers; rGO: reduced graphene oxide; E-M: PEDOT-Mo ${ }_{1.33} \mathrm{C}$ composite film.

Table S4. Comparison of our current work with the published two articles.

\begin{tabular}{|c|c|c|c|}
\hline & Current work & Article in $\mathrm{JMCA}^{16}$ & $\begin{array}{c}\text { Article in Adv. Funct. } \\
\text { Mater. }{ }^{17}\end{array}$ \\
\hline Reactants & $\begin{array}{c}\text { MXene }\left(\mathrm{Mo}_{1.33} \mathrm{C}, \mathrm{Ti}_{3} \mathrm{C}_{2} \mathrm{~T}_{\mathrm{x}}\right) \\
\text { and monomers }(\mathrm{EDOT}, \\
\text { Pyrrole })\end{array}$ & $\begin{array}{c}\mathrm{Ti}_{3} \mathrm{C}_{2} \mathrm{~T}_{\mathrm{x}} \text { and } \\
\text { monomer EDOT }\end{array}$ & $\begin{array}{c}\mathrm{Mo}_{1.33} \mathrm{C} \text { and } \\
\text { polymer PEDOT:PSS }\end{array}$ \\
\hline Apply electric filed & Yes & No & No \\
\hline $\begin{array}{c}\text { Polymerization } \\
\text { method }\end{array}$ & $\begin{array}{l}\text { Electrochemical } \\
\text { polymerization }\end{array}$ & $\begin{array}{l}\text { charge-transfer- } \\
\text { induced } \\
\text { polymerization }\end{array}$ & No \\
\hline Complex formation by & Electrochemical reaction & Chemical reaction & Physical mix \\
\hline Time & Short $(\sim 30 \mathrm{~min})$ & Long $(\sim 24 \mathrm{~h})$ & Long $(\sim 24 \mathrm{~h})$ \\
\hline $\begin{array}{l}\text { Main component in } \\
\text { final products }\end{array}$ & Polymer $(\sim 70 \%)$ & $\mathrm{Ti}_{3} \mathrm{C}_{2} \mathrm{~T}_{\mathrm{x}}(\sim 95 \%)$ & $\mathrm{Mo}_{1.33} \mathrm{C}(\sim 90 \%)$ \\
\hline $\begin{array}{l}\text { Composite film } \\
\text { formation method }\end{array}$ & $\begin{array}{c}\text { In situ electrochemical } \\
\text { polymerization }\end{array}$ & Vacuum filtration & Vacuum filtration \\
\hline $\begin{array}{l}\text { Possibility to obtain } \\
\text { Pattern in } \boldsymbol{\mu m}\end{array}$ & Yes & No & No \\
\hline
\end{tabular}


Overall, the method demonstrated in current manuscript is very different from the methods reported in the above two articles and has unique advantages. In addition, the universality of the method (MXene can promote the electrochemical polymerization of organic monomers without use of traditional electrolytes) was studied in the manuscript by choosing two classic organic monomers (Pyrrole and EDOT) and MXene $\left(\mathrm{Mo}_{1.33} \mathrm{C}, \mathrm{Ti}_{3} \mathrm{C}_{2} \mathrm{~T}_{\mathrm{x}}\right)$, which shows that the method is universal and not limited to a specific monomer.

\section{Reference:}

1. Tao, Q. Z. et al. Two-dimensional Mo1.33C MXene with divacancy order-ing prepared from parent 3D laminate with in-plane chemical ordering. Nat. Commun. 8, 14949 (2017).

2. Peng, $\mathrm{Y}-\mathrm{Y}$. et al. All-MXene (2D titanium carbide) solid-state microsupercapacitors for onchip energy storage. Energy Environ. Sci. 9, 2847-2854 (2016).

3. Lind, H., Halim, J., Simak, S. \& Rosen, J. Investigation of vacancy-ordered Mo1.33 C MXene from first principles and x-ray photoelectron spectroscopy. Phys. Rev. Mater. 1, 044002(2017).

4. Halim, J.et al. X-ray photoelectron spectroscopy of select multi-layered transition metal carbides (MXenes). Appl. Surf. Sci. 362, 406-417 (2016).

5. Peng, Y-Y. et al. All-MXene (2D titanium carbide) solid-state microsupercapacitors for onchip energy storage. Energy Environ. Sci. 9, 2847-2854 (2016).

6. Meng, C., Maeng, J., John, S. \& Irazoqui, P. Ultrasmall Integrated 3D Micro-Supercapacitors Solve Energy Storage for Miniature Devices. Adv. Energy Mater. 4, 1301269 (2014).

7. El-Kadya, M. et al. Engineering three-dimensional hybrid supercapacitors and microsupercapacitors for high-performance integrated energy storage. Proc. Natl. Acad. Sci. U.S.A. 112, 4233-4238 (2015).

8. $\mathrm{Pu}, \mathrm{X}$. et al. Wearable Textile-Based In-Plane Microsupercapacitors. Adv. Energy Mater. 1601254 (2016).

9. $\mathrm{Pu}, \mathrm{J}$. et al. Highly Stretchable Microsupercapacitor Arrays with Honeycomb Structures for Integrated Wearable Electronic Systems. ACS Nano 10, 9306-9315 (2016).

10. Zhu, M. et al. A Highly Durable, Transferable, and Substrate-Versatile High-Performance All-Polymer Micro-Supercapacitor with Plug-and-Play Function. Adv. Mater. 1605137 (2017).

11. Wu, C. et al. High-Performance Wearable Micro-Supercapacitors Based on MicrofluidicDirected Nitrogen-Doped Graphene Fiber Electrodes. Adv. Funct. Mater. 1702493 (2017).

12. Lin, Y., Gao, Y. \& Fan, Z. Printable Fabrication of Nanocoral-Structured Electrodes for High-Performance Flexible and Planar Supercapacitor with Artistic Design. Adv. Mater. 1701736 (2017).

13. Couly, C. et al. Asymmetric Flexible MXene-Reduced Graphene Oxide MicroSupercapacitor. Adv. Electron. Mater. 1700339 (2017). 
14. Zhang, C. et al. Stamping of Flexible, Coplanar Micro-Supercapacitors Using MXene Inks. Adv. Funct. Mater. 1705506 (2018).

15. Liu, W. et al. High-Performance Microsupercapacitors Based on Two-Dimensional Graphene/Manganese Dioxide/Silver Nanowire Ternary Hybrid Film. ACS Nano 9, 1528-1542 (2015).

16. Chen, C. et al. Charge Transfer Induced Polymerization of EDOT Confined Between 2D Titanium Carbide Layers. J. Mater. Chem. A 5, 5260-5265 (2017).

17. Qin, L. et al. High-Performance Ultrathin Flexible Solid-State Supercapacitors Based on Solution Processable Mo1.33C MXene and PEDOT:PSS. Adv. Fun. Mater. 28, 1703808 (2018). 